NBER WORKING PAPER SERIES

CLEARING UP THE FISCAL MULTIPLIER MORASS

\author{
Eric M. Leeper \\ Nora Traum \\ Todd B. Walker \\ Working Paper 17444 \\ http://www.nber.org/papers/w17444 \\ NATIONAL BUREAU OF ECONOMIC RESEARCH \\ 1050 Massachusetts Avenue \\ Cambridge, MA 02138 \\ September 2011
}

We would like to thank seminar participants at the Bank of Canada, the 2011 Bundesbank Spring Conference, the Federal Reserve Bank of Dallas, the 2011 Konstanz Seminar on Monetary Theory and Policy, the 2011 SED annual meeting, and Henning Bohn, Berthold Herrendorf, Giorgio Primiceri, Morten Raven and Harald Uhlig for helpful comments. The views expressed herein are those of the authors and do not necessarily reflect the views of the National Bureau of Economic Research.

NBER working papers are circulated for discussion and comment purposes. They have not been peerreviewed or been subject to the review by the NBER Board of Directors that accompanies official NBER publications.

(C) 2011 by Eric M. Leeper, Nora Traum, and Todd B. Walker. All rights reserved. Short sections of text, not to exceed two paragraphs, may be quoted without explicit permission provided that full credit, including $\odot$ notice, is given to the source. 
Clearing Up the Fiscal Multiplier Morass

Eric M. Leeper, Nora Traum, and Todd B. Walker

NBER Working Paper No. 17444

September 2011

JEL No. C11,E62,E63

\begin{abstract}
$\underline{\text { ABSTRACT }}$
Bayesian prior predictive analysis of five nested DSGE models suggests that model specifications and prior distributions tightly circumscribe the range of possible government spending multipliers. Multipliers are decomposed into wealth and substitution effects, yielding uniform comparisons across models. By constraining the multiplier to tight ranges, model and prior selections bias results, revealing less about fiscal effects in data than about the lenses through which researchers choose to interpret data. When monetary policy actively targets inflation, output multipliers can exceed one, but investment multipliers are likely to be negative. Passive monetary policy produces consistently strong multipliers for output, consumption, and investment.
\end{abstract}

Eric M. Leeper

Department of Economics

304 Wylie Hall

Indiana University

Bloomington, IN 47405

and Monash University, Australia

and also NBER

eleeper@indiana.edu

Nora Traum

Department of Economics

Nelson Hall Campus Box 8110

North Carolina State University

Raleigh, NC 27695

nora_traum@ncsu.edu
Todd B. Walker

Department of Economics

105 Wylie Hall

Indiana University

Bloomington, IN 47405

walkertb@indiana.edu 


\title{
Clearing Up the Fiscal Multiplier Morass*
}

\author{
Eric M. Leeper ${ }^{\dagger}$ Nora Traum ${ }^{\ddagger} \quad$ Todd B. Walker ${ }^{\S}$
}

\section{INTRODUCTION}

Quantitative estimates of fiscal multipliers are the nub of the policy and academic debate about the efficacy of the fiscal stimulus packages implemented in response to the recent recession and financial crisis. Estimates vary widely. Government spending multipliers for output range from -0.26 to well over 1.0 on impact and from below -1.0 to about 1.40 in the very long run [Davig and Leeper (2011), Drautzburg and Uhlig (2011), Uhlig (2009, 2010)]. Ranges like these make it difficult for economists to formulate fiscal policy advice.

One active area of research seeks to understand the economic mechanisms underlying the size of multipliers for unproductive government spending. That work uncovers a long list of important model features. Galí, López-Salido, and Vallés (2007) and Forni, Monteforte, and Sessa (2009) point to both the fraction of hand-to-mouth (liquidity-constrained or rule-of-thumb) consumers and the degree of real rigidities. Monacelli and Perotti (2008) highlight wealth effects and nominal rigidities. Bilbiie (2011) and Monacelli and Perotti (2008) suggest non-separability in preferences over consumption and leisure. Leeper, Plante, and Traum (2010) and Uhlig (2010) emphasize distorting fiscal financing. And many studies show that monetary policy behavior matters [Kim (2003), Bilbiie, Meier, and Müller (2008), Eggertsson (2009), Zubairy (2010), Christiano, Eichenbaum, and Rebelo (2011), and Davig and Leeper (2011)].

Two recent meta-studies illustrate the state of the fiscal multiplier literature. The meta-studies employ suites of models that embed a variety of fiscal transmission mechanisms and confront similar time series data, but draw strikingly different conclusions. One study calculates government spending multipliers for seven structural models and concludes that sizeable short-run output mul-

\footnotetext{
*We would like to thank seminar participants at the Bank of Canada, the 2011 Bundesbank Spring Conference, the Federal Reserve Bank of Dallas, the 2011 Konstanz Seminar on Monetary Theory and Policy, the 2011 SED annual meeting, and Henning Bohn, Berthold Herrendorf, Giorgio Primiceri, Morten Raven and Harald Uhlig for helpful comments.

${ }^{\dagger}$ Indiana University, Monash University and NBER; eleeper@indiana.edu.

${ }^{\ddagger}$ North Carolina State University; nora_traum@ncsu.edu

§Indiana University; walkertb@indiana.edu.
} 
tipliers are a robust feature across models [Coenen, Erceg, Freedman, Furceri, Kumhof, Lalonde, Laxton, Lindé, Mourougane, Muir, Mursula, de Resende, Roberts, Roeger, Snudden, Trabandt, and in't Veld (2010), hereafter referred to as IMF10/73]. A second study considers a set of models with many of the same mechanisms as in IMF10/73, but concludes that impact multipliers are substantially below unity [Cogan, Cwik, Taylor, and Wieland (2010) and Cwik and Wieland (2011)]. Within the same class of models, Drautzburg and Uhlig (2011) estimate short-run multipliers of one-half and long-run multipliers of about negative one-half.

When closely-related economic models are fit to similar data but yield very different estimates of multipliers, the literature has entered a morass. This paper aims to clear up the morass.

To begin the clarification process, we examine fiscal multipliers from five nested models: (1) a simple real business cycle (RBC) model; (2) the RBC model with real frictions added; (3) the RBC model with nominal rigidities included (a basic new Keynesian model); (4) the new Keynesian model with hand-to-mouth agents; and (5) the new Keynesian model extended to an open economy. Our work, like the research cited above, limits attention to unproductive government spending.

In all but the simplest versions of these models, the government spending multiplier is a complicated object: an unknown non-linear function of all the model parameters. Bayesian prior predictive analysis is a powerful tool to shed light on complicated objects of interest-like the spending multiplier - that depend on both the joint prior distribution of parameters and the model specification. $^{1}$

We apply prior predictive analysis sequentially to the nested models to systematically isolate the aspects of each model specification that are important for determining the size of the government spending multiplier. The analysis yields precise statements about how particular mechanisms trigger wealth and substitution effects that change the multiplier in models-like those in the meta-studies - that are rich enough to be empirically relevant.

Model features like wage rigidities, which can flip the sign of the substitution effect created by higher government spending - from negative to positive - contribute to producing a large multiplier. Analogously, the presence of rule-of-thumb consumers, who do not factor in the higher future taxes associated with higher government spending, attenuate negative wealth effects to increase the multiplier. Although the models can produce output multipliers greater than one, it is difficult for any of the model specifications to produce very large multipliers.

The bulk of our results, like most of the existing literature, conditions on a policy regime in which monetary policy is actively targeting inflation and fiscal policy is passively adjusting surpluses to stabilize government debt. Active monetary policy reacts to a persistent fiscal expansion and the attendant increase in inflation by sharply raising the nominal policy interest rate. This raises the real interest rate, which reduces consumption and investment demand to attenuate the stimulative effects of the fiscal expansion. It is not too surprising that in this monetary-fiscal regime, very large fiscal multipliers are unlikely.

Since the 2007-2009 recession, many central banks have shifted their emphasis from stabilizing

\footnotetext{
${ }^{1}$ Lancaster (2004) and Geweke (2005, 2010) provide textbook treatments.
} 
inflation to stimulating demand by maintaining low and constant policy interest rates - near zero in some economies. When monetary policy makes the interest rate unresponsive to inflation, a "passive" stance, it amplifies fiscal policy's impacts. By fixing the interest rate, monetary policy allows higher current and expected inflation to transmit into lower real interest rates. Instead of attenuating the demand stimulus of a fiscal expansion, monetary policy amplifies it: lower real rates encourage greater consumption and investment demand. Lower real rates induce a positive substitution effect from higher government spending, substantially raising output, consumption, and investment multipliers. In sharp contrast to the active monetary/passive fiscal regime, it is very difficult to obtain small spending multipliers from the mix of passive monetary/active fiscal policy.

Of course, DSGE models impose economic structure and, therefore, restrictions on data. But when the model and the prior constrain the fiscal multiplier to exceptionally narrow rangeseven before confronting data - then the studies bias results. Such studies reveal less about the fiscal effects that are embedded in time series data than they do about the lenses through which researchers choose to interpret the data.

\section{The Models}

Our models share several details with the class of models used to evaluate the size of fiscal multipliers: (1) forward-looking, optimizing agents; (2) households who receive utility from consumption and leisure; (3) production sectors that use capital and labor inputs; (4) monopolistic competition in the goods and labor sectors; (5) empirically relevant nominal and real frictions; (6) fiscal and monetary authorities who set their instruments using simple feedback rules; and (7) the economy is at its cashless limit.

Our broadest model, an open economy new Keynesian model similar to Adolfson, Laseen, Lindé, and Villani (2007), nests four models that are commonly used to study fiscal multipliers - a basic Real Business Cycle (RBC) model, an RBC model with real frictions, a standard new Keynesian (NK) model, and a NK model with nonsavers. We now describe the main model and the restrictions that deliver the nested models.

The world economy consists of two large countries, Home $(\mathrm{H})$ and Foreign $(\mathrm{F})$, with symmetric preferences. Public and private consumption and investment consist of domestically produced and imported goods. In the short run, the pass-through of the nominal exchange rate to export and import prices is incomplete due to local currency pricing.

2.1 Households The economy is populated by a continuum of households on the interval $[0,1]$, of which a fraction $\mu$ are non-savers and a fraction $1-\mu$ are savers. The superscript $S$ indicates a variable associated with savers and $N$ with non-savers.

2.1.1 SAVERS An optimizing representative saver household $j$ derives utility from consumption, $c_{t}^{S}(j)$, relative to a habit stock defined in terms of lagged aggregate consumption of savers $\left(\theta C_{t-1}^{S}\right.$ where $\theta \in[0,1))$, and derives disutility from hours worked, $l_{t}^{S}(j)$ : 


$$
E_{t} \sum_{t=0}^{\infty} \beta^{t}\left[\frac{\left(c_{t}^{S}(j)-\theta C_{t-1}^{S}\right)^{1-\gamma}}{1-\gamma}-\frac{l_{t}^{S}(j)^{1+\xi}}{1+\xi}\right]
$$

where $\beta$ is the discount rate, $\gamma$ is the household's risk aversion, and $\xi$ is the inverse of the Frisch labor elasticity. Savers receive interest income from domestic and international one-period risk free nominal bond holdings, after tax wage income, after tax rental income from capital, lump sum transfers from the government $Z^{S}$, and profits from firms $D$. Savers spend income on consumption, investment in future capital $i^{S}$, and the domestic and international bonds, $B^{S}$ and $F^{S}$ respectively. The flow budget constraint for saver $j$ is

$$
\begin{aligned}
& P_{t}^{C}\left(1+\tau_{t}^{c}\right) c_{t}^{S}(j)+P_{t}^{I} i_{t}^{S}(j)+B_{t}^{S}(j)+F_{t}^{S}(j)=R_{t-1} B_{t-1}^{S}(j)+R_{t-1}^{*} S_{t}\left[1-\Gamma_{f}(\cdot)\right] F_{t-1}^{S}(j)+\left(1-\tau_{t}^{l}\right) \int_{0}^{1} W_{t}(l) l_{t}^{S}(j, l) d l \\
& +\left(1-\tau_{t}^{k}\right) R_{t}^{k} v_{t}(j) \bar{k}_{t-1}^{S}(j)-\psi\left(v_{t}\right) \bar{k}_{t-1}^{S}+P_{t}^{C} Z_{t}^{S}(j)+D_{t}(j)
\end{aligned}
$$

Nominal consumption, $P^{C} C$, is subject to a sales tax $\tau^{C}$. $P^{I}$ denotes the price of investment goods, which potentially differs from consumption goods as they may consist of different bundles of traded and nontraded goods.

Each household $j$ supplies a continuum of differentiated labor inputs, $l_{t}^{S}(j, l)$, on the interval $[0,1]$, which ensures all households have the same labor income in equilibrium. $W_{t}(l)$ is the nominal wage rate for labor input $l$, and $\int_{0}^{1} W_{t}(l) l_{t}^{S}(j, l) d l$ is the total nominal labor income for household $j$. Total labor income is taxed at the rate $\tau^{l}$.

Savers have access to an international risk-free nominal bond, $F^{S}$, that pays gross nominal interest $R^{*} . \Gamma_{f}(\cdot)$ is a risk premium on foreign bonds that depends on the net foreign asset position of the home economy and ensures stationarity. Specifically, the risk premium is defined as $\Gamma_{f}\left(\frac{s_{t} F_{t}}{Y_{t}}\right)=\gamma_{f}\left(\exp \left(\frac{s_{t} F_{t}}{Y_{t}}\right)-1\right)$, where $s_{t}$ is the real exchange rate, which is defined as the ratio of consumption prices expressed in the same currency, $s_{t} \equiv S_{t} P_{t}^{C *} / P_{t}^{C}$, and $S_{t}$ is the nominal exchange rate, expressed as the price of one domestic consumption basket in terms of foreign consumption.

Effective capital is related to the physical capital stock $\bar{k}$ by $k_{t}^{s}(j)=v_{t}(j) \bar{k}_{t-1}^{S}(j)$, where $v_{t}(j)$ is the utilization rate of capital. This utilization incurs a cost of $\Psi\left(v_{t}\right)$ per unit of physical capital. In the steady state, $v=1$ and $\Psi(1)=0$. Define a parameter $\psi \in[0,1)$ such that $\frac{\Psi^{\prime \prime}(1)}{\Psi^{\prime}(1)} \equiv \frac{\psi}{1-\psi}$, as in Smets and Wouters (2003). As $\psi \rightarrow 1$, the utilization cost becomes infinite, and the capital utilization rate becomes constant. Rental income on effective capital is taxed at the rate $\tau^{k}$. The law of motion for physical capital is given by

$$
\bar{k}_{t}^{S}(j)=(1-\delta) \bar{k}_{t-1}^{S}(j)+\left[1-\Gamma_{i}\left(\frac{i_{t}^{S}(j)}{i_{t-1}^{S}(j)}\right)\right] i_{t}^{S}(j)
$$

where $\Gamma_{i}(\cdot) i_{t}^{S}$ is an investment adjustment cost, as in Smets and Wouters (2003) and Christiano, Eichenbaum, and Evans (2005) and satisfies $\Gamma_{i}(1)=s^{\prime}(1)=0$, and $s^{\prime \prime}(1) \equiv s>0$. Investment costs decrease as $s$ declines. 
2.1.2 Wage Setting and Labor Aggregation Households supply differentiated labor services to the intermediate goods producing firms. Each differentiated labor service is supplied by both savers and non-savers, and demand is uniformly allocated among households. A perfectly competitive labor packer purchases the differentiated labor inputs and assembles them to produce a composite labor service, $L_{t}$, according to

$$
L_{t}=\left[\int_{0}^{1} l_{t}(l)^{\frac{1}{1+\eta^{w}}} d l\right]^{1+\eta^{w}}
$$

where $\eta^{w}$ is the wage markup. The competitive labor packer's demand function comes from solving its profit maximization problem subject to (1), to yield

$$
l_{t}(l)=L_{t}^{d}\left(\frac{W_{t}(l)}{W_{t}}\right)^{-\frac{1+\eta^{w}}{\eta^{w}}}
$$

where $L_{t}^{d}$ is the demand for composite labor services, and $W_{t}$ is the aggregate nominal wage.

Substantial variation in modeling wage-setting decisions exists in the literature. ${ }^{2}$ We follow the approach of assuming savers optimally set their wage while non-savers simply set their wage to be the average wage of the savers [examples include Erceg, Guerrieri, and Gust (2006) and Forni, Monteforte, and Sessa (2009)]. Since non-savers face the same labor demand schedule as savers, they work the same number of hours as the average for savers.

Every period, saver households receive signals to reset their nominal wages for each differentiated labor service with probability $\left(1-\omega_{w}\right)$. Those who cannot reoptimize partially index their wages to past inflation according to the rule, $W_{t}(l)=W_{t-1}(l) \pi_{t-1}^{\chi^{w}}$, where $\chi^{w} \in[0,1]$ measures the degree of backward indexation. Savers that receive the signal choose the nominal wage rate $W_{t}(l)$ to maximize their utility. Finally, the nominal aggregate wage evolves according to

$$
W_{t}=\left[\left(1-\omega_{w}\right) \widetilde{W}_{t}^{\frac{-1}{\eta^{w}}}+\omega_{w}\left(\pi^{1-\chi^{w}} \pi_{t-1}^{\chi^{w}}\right)^{\frac{-1}{\eta^{w}}} W_{t-1}^{\frac{-1}{\eta^{w}}}\right]^{-\eta^{w}}
$$

where $\widetilde{W}_{t}$ is the optimal nominal wage rate chosen by savers at time $t$.

2.1.3 Non-SAVERS Non-savers have the same preferences as savers. Non-savers are rule-ofthumb agents who each period must consume their entire disposable income, which consists of after tax labor income and lump-sum transfers from the government $Z^{N}$. The budget constraint for a non-saver $j \in(\mu, 1]$ is

$$
\left(1+\tau_{t}^{C}\right) P_{t}^{C} c_{t}^{N}(j)=\left(1-\tau_{t}^{l}\right) W_{t} L_{t}^{N}(j)+P_{t}^{C} Z_{t}^{N}(j)
$$

\footnotetext{
${ }^{2}$ For example, in whether or not non-savers are allowed to optimally choose their wage and in how wages are chosen.
} 
Non-savers nominal consumption $P^{C} C^{N}$ is subject to the same tax rate as savers, $\tau^{C}$. Non-savers nominal wage income, $W_{t} L_{t}^{N}$ also is subject to the same tax rate as savers, $\tau^{l}$. Since non-savers work the same number of hours as the average for savers, and nominal wages are determined by savers, non-savers consumption is determined by the budget constraint (4).

\subsection{Firms And Price Setting}

2.2.1 Intermediate Goods Firms Each country consists of a continuum of monopolistically competitive intermediate goods firms (indexed by $i \in[0,1]$ ). These firms charge different prices at home and abroad, as in Betts and Devereux (1996). In the home market, the demand for firm $i$ 's output $y_{t}^{H}(i)$ is given by

$$
y_{t}^{H}(i)=Y_{t}^{H}\left(\frac{p_{t}^{H}(i)}{P_{t}^{H}}\right)^{-\frac{1+\eta_{p}}{\eta_{p}}}
$$

where $\eta_{p}>0, p_{t}^{H}(i)$ is the output price in the home market charged by firm $i, Y_{t}^{H}$ is aggregate domestic demand, and $P_{t}^{H}$ is the aggregate domestic price index. Likewise, in the foreign market, the demand for firm $i$ 's output is

$$
m_{t}(i)=M_{t}^{*}\left(\frac{p_{t}^{H *}(i)}{P_{t}^{H *}}\right)^{-\frac{1+\eta_{p}}{\eta_{p}}}
$$

where $m_{t}(i)$ denotes the foreign quantity demanded of home good $i, p_{t}^{H *}(i)$ is the price that firm $i$ charges in the foreign market, $P_{t}^{H *}$ is the foreign import price index, and $M_{t}^{*}$ denotes aggregate foreign imports.

Each individual firm $i$ produces with a Cobb-Douglas technology, $y_{t}(i)=A_{t} k_{t}(i)^{\alpha} l_{t}(i)^{1-\alpha}$, where $\alpha \in[0,1]$. There are no fixed costs of production, as in Del Negro, Schorfheide, Smets, and Wouters (2004). Firms face perfectly competitive factor markets for capital and labor. Cost minimization implies that the firms have identical nominal marginal costs per unit of output, given by $M C_{t}=(1-\alpha)^{\alpha-1} \alpha^{-\alpha}\left(R_{t}^{k}\right)^{\alpha} W_{t}^{1-\alpha} A_{t}^{-1}$.

Home and foreign prices evolve by a Calvo (1983) mechanism. An intermediate firm has a probability of $\left(1-\omega_{p}\right)$ each period to reoptimize its price at home and a probability of $\left(1-\omega_{p, x}\right)$ each period to reoptimize its price abroad. Firms that cannot reoptimize partially index their prices to past inflation according to the rules

$$
p_{t}^{H}(i)=\left(\pi_{t-1}^{H}\right)^{\chi_{p}}\left(\pi^{H}\right)^{1-\chi_{p}} P_{t-1}^{H}(i), \quad p_{t}^{H *}(i)=\left(\pi_{t-1}^{H *}\right)^{\chi_{p, x}}\left(\pi^{H *}\right)^{1-\chi_{p, x}} P_{t-1}^{H *}(i)
$$

where $\pi_{t-1}^{H} \equiv P_{t-1}^{H} / P_{t-2}^{H}$ and $\pi_{t-1}^{H *} \equiv P_{t-1}^{H *} / P_{t-2}^{H *}$.

Firms that are allowed to reoptimize their price in the domestic market in period $t$ maximize expected discounted nominal profits

$$
E_{t} \sum_{s=0}^{\infty}\left(\beta \omega_{p}\right)^{s} \frac{\lambda_{t+s}}{\lambda_{t}}\left[\left(\prod_{k=1}^{s}\left(\pi_{t+k-1}^{H}\right)^{\chi_{p}}\left(\pi^{H}\right)^{1-\chi_{p}}\right) p_{t}^{H}(i) y_{t+s}^{H}(i)-M C_{t+s} y_{t+s}^{H}(i)\right]
$$


subject to (5). Analogously, firms that are allowed to reoptimize their price in the foreign market in period $t$ maximize

$$
E_{t} \sum_{s=0}^{\infty}\left(\beta \omega_{p, x}\right)^{s} \frac{\lambda_{t+s}}{\lambda_{t}}\left[\left(\prod_{k=1}^{s}\left(\pi_{t+k-1}^{H *}\right)^{\chi_{p, x}}\left(\pi^{H *}\right)^{1-\chi_{p, x}}\right) p_{t}^{H *}(i) S_{t+s} m_{t+s}(i)-M C_{t+s} m_{t+s}(i)\right]
$$

subject to (6).

2.2.2 Final Goods Firms Three distinct types of final-good firms combine the domestically produced and imported intermediate goods to produce the three final non-tradable goods: a private consumption good, a private investment good, and a public consumption good.

The final private consumption good $Q_{t}^{C}$ is produced by combining a bundle of domesticallyproduced intermediate goods $C_{t}^{H}$ with a bundle of imported foreign intermediate goods, $C_{t}^{F}$ via the technology

$$
Q_{t}^{C}=\left[\left(1-\nu_{C}\right)^{\frac{1}{\mu_{C}}}\left(C_{t}^{H}\right)^{\frac{\mu_{C}-1}{\mu_{C}}}+\nu_{C}^{\frac{1}{\mu_{C}}}\left(C_{t}^{F}\right)^{\frac{\mu_{C}-1}{\mu_{C}}}\right]^{\frac{\mu_{C}}{\mu_{C}-1}}
$$

where $\mu_{C}>0$ is the elasticity of substitution between home and foreign goods, $\nu_{C} \in[0,1]$ determines the relative preference a country has for domestic and foreign goods. Home and foreign intermediate goods bundles combine differentiated output from each domestic firm $i$ and foreign firm $i^{*}$ via

$$
C_{t}^{H}=\left[\int_{0}^{1} C_{t}^{H}(i)^{\frac{1}{1+\eta_{p}}} d i\right]^{1+\eta_{p}} \quad C_{t}^{F}=\left[\int_{0}^{1} C_{t}^{F}\left(i^{*}\right)^{\frac{1}{1+\eta_{p, x}}} d i\right]^{1+\eta_{p, x}}
$$

where $\eta_{p}, \eta_{p, x}>0$ are related to the intratemporal elasticities of substitution between the differentiated outputs supplied by the home and foreign intermediate firms. The consumption final good firm first chooses optimal amounts of each differentiated output from firms $i$ and $i^{*}$ via cost minimization, and then chooses the optimal bundles to maximize profits. Similarly, the final private investment good $Q_{t}^{I}$ and the public consumption good $Q_{t}^{G}$ are produced via the technologies

$$
Q_{t}^{I}=\left[\left(1-\nu_{I}\right)^{\frac{1}{\mu_{I}}}\left(I_{t}^{H}\right)^{\frac{\mu_{I}-1}{\mu_{I}}}+\nu_{I}^{\frac{1}{\mu_{I}}}\left(I_{t}^{F}\right)^{\frac{\mu_{I}-1}{\mu_{I}}}\right]^{\frac{\mu_{I}}{\mu_{I}-1}} \quad Q_{t}^{G}=\left[\left(1-\nu_{G}\right)^{\frac{1}{\mu_{G}}}\left(G_{t}^{H}\right)^{\frac{\mu_{G}-1}{\mu_{G}}}+\nu_{G}^{\frac{1}{\mu_{G}}}\left(G_{t}^{F}\right)^{\frac{\mu_{G}-1}{\mu_{G}}}\right]^{\frac{\mu_{G}}{\mu_{G}-1}}
$$

where

$$
\begin{aligned}
I_{t}^{H} & =\left[\int_{0}^{1} I_{t}^{H}(i)^{\frac{1}{1+\eta_{p}}} d i\right]^{1+\eta_{p}} \quad I_{t}^{F}=\left[\int_{0}^{1} I_{t}^{F}\left(i^{*}\right)^{\frac{1}{1+\eta_{p, x}}} d i\right]^{1+\eta_{p, x}} \\
G_{t}^{H} & =\left[\int_{0}^{1} G_{t}^{H}(i)^{\frac{1}{1+\eta_{p}}} d i\right]^{1+\eta_{p}} \quad G_{t}^{F}=\left[\int_{0}^{1} G_{t}^{F}\left(i^{*}\right)^{\frac{1}{1+\eta_{p, x}}} d i\right]^{1+\eta_{p, x}}
\end{aligned}
$$

2.3 Monetary Policy The monetary authority follows a Taylor-type rule, in which the domestic nominal interest rate $R_{t}$ responds to its lagged value, the current consumption inflation rate, and current output. We denote a variable in percentage deviations from steady state by a hat. The 
interest rate is set according to

$$
\hat{R}_{t}=\rho_{r} \hat{R}_{t-1}+\left(1-\rho_{r}\right)\left[\phi_{\pi} \hat{\pi}_{t}^{C}+\phi_{y} \hat{Y}_{t}\right]+\epsilon_{t}^{m}, \quad \epsilon_{t}^{m} \sim N(0,1) .
$$

2.4 Fiscal Policy Each period the government collects tax revenues from capital, labor, and consumption taxes, and issues one-period nominal bonds, $B_{t}$, to finance its interest payments and expenditures, $G_{t}, Z_{t}^{S}, Z_{t}^{N}$. The nominal flow government budget constraint is

$$
B_{t}+\tau_{t}^{K} R_{t}^{K} v_{t} K_{t-1}+\tau_{t}^{L} W_{t} L_{t}+P_{t}^{C} \tau_{t}^{C} C_{t}=R_{t-1} B_{t-1}+P_{t}^{G} G_{t}+P_{t}^{C}\left(Z_{t}^{S}+Z_{t}^{N}\right)
$$

Fiscal rules are simple. They include a response of fiscal instruments to the debt-GDP ratioto ensure that policies are sustainable - and an autoregressive term to allow for serial correlation. Fiscal instruments evolve according to the following rules:

$$
\begin{gathered}
\hat{\tau}_{t}^{\mathcal{J}}=\rho_{\mathcal{J}} \hat{\tau}_{t-1}^{\mathcal{J}}+\left(1-\rho_{\mathcal{J}}\right) \gamma_{\mathcal{J}} \hat{s}_{t-1}^{b}+\epsilon_{t}^{\mathcal{J}}, \quad \hat{\tau}_{t}^{C}=\rho_{C} \hat{\tau}_{t-1}^{C}+\epsilon_{t}^{C} \\
\hat{G}_{t}=\rho_{G} \hat{G}_{t-1}-\left(1-\rho_{G}\right) \gamma_{G} \hat{s}_{t-1}^{b}+\epsilon_{t}^{G}, \quad \hat{Z}_{t}^{\mathcal{Q}}=\rho_{Z \mathcal{Q}} \hat{Z}_{t-1}^{\mathcal{Q}}-\left(1-\rho_{Z \mathcal{Q}}\right) \gamma_{Z \mathcal{Q}} \hat{s}_{t-1}^{b}+\epsilon_{t}^{Z \mathcal{Q}}
\end{gathered}
$$

where $\mathcal{J}=K, L, \mathcal{Q}=S, N$ and $s_{t-1}^{b} \equiv \frac{B_{t-1}}{Y_{t-1}}$, and $\epsilon_{t}^{s} \sim$ i.i.d. $N(0,1)$ for $s=\{K, L, C, G, Z S, Z N\}$.

\subsection{Resource Constraint and Net Foreign Assets Let $X_{t}$ denote the aggregate quantity} of a variable $x_{t}$. Aggregate home consumption is defined as the sum of the two types of household consumption goods: $C_{t}=\int_{0}^{1} c_{t}(j) d j=\mu C_{t}^{S}+(1-\mu) C_{t}^{N}$. Market clearing in the final-good markets implies $Q_{t}^{C}=C_{t}, Q_{t}^{I}=I_{t}+\psi\left(v_{t}\right) \bar{K}_{t-1}, Q_{t}^{G}=G_{t}$. The home country's aggregate resource constraint is $Y_{t}=C_{t}^{H}+I_{t}^{H}+G_{t}^{H}+M_{t}^{*}$ where foreign imports are defined as $M_{t}^{*} \equiv C_{t}^{H *}+I_{t}^{H *}+G_{t}^{H *}$. Net foreign assets evolve according to

$$
S_{t} F_{t}=R_{t-1}^{*} S_{t}\left[1-\Gamma_{f}(\cdot)\right] F_{t-1}+S_{t} P_{t}^{H *} M_{t}^{*}-P_{t}^{F} M_{t}
$$

We define the domestic terms of trade, $T O T_{t}$, as the ratio between the import price and domestically produced price levels in domestic currency terms: $T O T_{t}=\frac{P_{t}^{F}}{S_{t} P_{t}^{H *}}$.

2.6 Nested Models The open-economy model is sufficiently rich to nest a wide range of models that are commonly used to examine the size of the fiscal multiplier. Table 1 lists the specific parameter restrictions that deliver each of the five nested models. Model 1 eliminates all real and nominal frictions to reduce to a standard RBC closed-economy model. Model 2 allows for real frictions (investment adjustment costs, habit formation, and capacity utilization) but eliminates the nominal frictions and the open economy aspects. Model 3 is a standard NK model with sticky prices and wages, which introduces a role for monetary-fiscal policy interactions. Model 4 adds non-savers to the standard NK model. And model 5 allows for an open-economy structure. ${ }^{3}$

\footnotetext{
${ }^{3}$ We restrict the open-economy model in the text so that the economy does not have access to international financial markets and government spending is completely home-biased. Ours is the open-economy version of the model that delivers the largest output multipliers. Results from alternative setups with fewer model restrictions appear in the
} 


\begin{tabular}{ll}
\hline & Parameter Restrictions \\
\hline Model 1: Basic RBC & $\psi=1, \theta=s=\omega_{w}=\omega_{p}=\eta^{w}=\eta^{p}=\chi^{w}=\chi^{p}=0$ \\
& $\phi_{\pi}=\phi_{y}=\rho_{r}=\mu=\nu^{C}=\nu^{I}=\nu^{G}=0$ \\
Model 2: RBC Real Frictions & $\omega_{w}=\omega_{p}=\eta^{w}=\eta^{p}=\chi^{w}=\chi^{p}=\phi_{\pi}=\phi_{y}=\rho_{r}=0$ \\
& $\mu=\nu^{C}=\nu^{I}=\nu^{G}=0$ \\
Model 3: NK Sticky Price \& Wage & $\mu=\nu^{C}=\nu^{I}=\nu^{G}=0$ \\
Model 4: NK Nonsavers & $\nu^{C}=\nu^{I}=\nu^{G}=0$ \\
Model 5: NK Open Economy & $\nu^{G}=0, \gamma_{f}=\inf$ \\
\hline
\end{tabular}

Table 1: Parameter restrictions on the main model that deliver nested models.

\section{Prior Predictive Analysis}

While simple DSGE models that permit analytical calculations of the multiplier are important for building economic intuition (e.g., Woodford (2011), Uhlig (2010)), they cannot be taken to data in a serious way. Conversely, models that include real and nominal frictions have been shown to fit data well but are sufficiently complicated that clean analytics are not available. We echo Geweke (2010) and Faust and Gupta (2010) in arguing for the use of prior predictive analysis to shed light on the black-box nature of empirically validated DSGE models. Prior predictive analysis pinpoints precisely which elements of the model are most important in determining the fiscal multiplier and it delivers the possible range of the multiplier conditional on a specific model. Most of the DSGE models that have played a role in the fiscal policy debate impose a tight range on the fiscal multiplier, as section 4 shows.

Before describing the prior predictive methodology, we establish some notation. Using the notation and language of Geweke (2010), a complete model contains four elements:

i. A probability density of observables conditional on unobservables $p\left(y_{T} \mid \theta_{A_{j}}, A_{j}\right)$ where $j=$ $1, \ldots, n$ denotes the number of models under consideration, $A_{j}$ denotes model $j, y_{T}$ denotes the vector of random ex ante observable, and $\theta_{A_{j}}$ are the unobservables. Evaluating this density at the ex post realized observables (i.e., data) yields the likelihood function $L\left(\theta_{A_{j}} ; y_{T}^{o}\right)=$ $p\left(y_{T}^{o} \mid \theta_{A_{j}}, A_{j}\right)$. For our purposes, this density is given by the log-linearized DSGE model described in section 2 and the nested models listed in table 1 . The vector $\theta_{A_{j}}$ denotes the parameters of the various DSGE models.

ii. A prior density function $p\left(\theta_{A, j} \mid A_{j}\right)$, which specifies the range of values and the probabilities the unobserved parameters take those values. Calibration, which is well known in the macroeconomics literature, is an example of a degenerate or dogmatic prior density.

iii. A vector of interest, $\omega$, and its corresponding distribution $p\left(\omega_{T} \mid y_{T}, \theta_{A, j}, A_{j}\right)$. Our vector of interest is the fiscal multiplier, which we define formally below. As the conditional distribution makes explicit, the fiscal multiplier will depend on the choice of model $\left(A_{j}\right)$, observables $\left(y_{T}\right)$, and unobservable parameters $\left(\theta_{A, j}\right)$.

appendix. 
iv. A Bayes action or decision, $\hat{d}_{T}=\operatorname{argmax}_{d_{T}} E\left[U\left(\omega_{T}, d_{T} \mid y_{T}^{o}, A_{j}\right)\right]$, which determines the optimal action and can be cast into the expected utility framework of von Neumann and Morgenstern.

The four model elements are straightforwardly related. The first two elements yield the posterior distribution $p\left(\theta_{A, j} \mid y_{t}^{o}, A_{j}\right)=p\left(\theta_{A, j} \mid A_{j}\right) p\left(y_{T}^{o} \mid \theta_{A_{j}}, A_{j}\right) / p\left(y_{T}^{o}\right)$, which is then used to obtain the posterior of the vector of interest according to $p\left(\omega_{T} \mid y_{T}^{o}, A_{j}\right)=\int_{\Theta_{A, j}} p\left(\omega_{T} \mid y_{T}^{o}, \theta_{A, j}, A_{j}\right) p\left(\theta_{A, j} \mid y_{T}^{o}, A_{j}\right) d \theta_{A, j}$. This distribution is then used to calculate the conditional expectation associated with the Bayes action, $\hat{d}_{T}$.

In the context of fiscal multipliers, a Bayes decision might be whether or not to implement expansionary fiscal policy. Debate surrounding the American Recovery and Reinvestment Act was couched in terms of fiscal multipliers. Romer and Bernstein (2009) argued that sizeable multipliers favor a large stimulus. Conditioning on similar data, Cogan, Cwik, Taylor, and Wieland (2010) took the opposite view, citing a much smaller multiplier. This paper takes a step back: we fix the vector of interest to focus exclusively on multipliers but we do not formulate/evaluate a decision rule. We focus on the importance of steps [i] and [ii] of the model building process, and advocate using a prior predictive analysis to illuminate how these initial steps may influence the vector of interest and, ultimately, the Bayes action that is being considered.

Elements [i] and [ii] of a complete model imply an ex-ante predictive distribution for the observables

$$
p\left(y_{T} \mid A_{j}\right)=\int_{\Theta_{A_{j}}} p\left(\theta_{A, j} \mid A_{j}\right) p\left(y_{T} \mid \theta_{A, j} A_{j}\right) d \theta_{A, j}
$$

This distribution gives the prior distribution of observables before data is collected. Computationally, it is straightforward and nearly costless to simulate from (14). The algorithm draws from $\theta_{A_{j}}^{(m)} \sim p\left(\theta_{A, j} \mid A_{j}\right)$, and $y_{T}^{(m)} \sim p\left(y_{T} \mid \theta_{A_{j}}^{(m)}, A_{j}\right)$. Drawing sequentially from these distributions delivers (14) and any function of $y_{T}$ including the vector of interest, $\omega^{(m)}$. We use the model specification and a prior distribution to obtain the range of values of the fiscal multiplier that the DSGE models deliver. Because prior predictive analysis gives the entire range of possible multipliers produced by the model and prior, we can evaluate the model before taking it to data. In the limiting case of totally uninformative data, the prior predictive becomes the posterior distribution.

In all model specifications we fix a few parameters whose values are standard in the literature. The discount factor, $\beta$, is set to 0.99 to imply an annual steady-state real interest rate of 4 percent. The capital income share of total output, $\alpha$, is set to 0.36 , implying a labor income share of 0.64 . The quarterly depreciation rate for private capital, $\delta$, is set to 0.025 so that the annual depreciation rate is 10 percent. The steady-state inflation rate, $\pi$, is 1 .

Steady-state fiscal variables are calibrated to the values in Traum and Yang (2010), which are mean values from U.S. data over the period 1983Q1-2008Q1. ${ }^{4}$ The federal government consumption

\footnotetext{
${ }^{4}$ We also adopted priors for these steady-state values and repeated the prior predictive analysis while allowing the fiscal steady-state values to vary. Results in the appendix show that short-run fiscal multipliers are largely insensitive to variations in steady-state fiscal parameters, but long-run multipliers are more sensitive.
} 
to output share is 0.074 , the federal debt to annualized output share is 0.386 , the average marginal federal labor tax rate is 0.209 , the capital tax rate is 0.196 , and finally, the consumption tax rate is 0.015 .

Table 2 lists the priors used in our analysis and figure 1 plots the prior distributions for each parameter. The priors were chosen to cover the range of parameter values considered in the calibrated exercises of IMF10/73 and Cwik and Wieland (2011). In addition, our priors are similar to those employed for Bayesian estimation of similar models [examples include Coenen and Straub (2004), Forni, Monteforte, and Sessa (2009), Lopez-Salido and Rabanal (2006), Leeper, Plante, and Traum (2010), and Traum and Yang (2010)].

Parameters related to openness are less common in the literature. The prior means of the substitution elasticity between foreign and domestic private consumption, investment, and government spending goods are set to 1.5, as in Chari, Kehoe, and McGrattan (2002) and IMF10/73. The standard deviations are set so that the priors reflect a range of values from calibration and estimation exercises. The prior means for the share of imports in private consumption, investment, and government spending bundles are set to 0.25 . Although the risk premium parameter $\gamma_{f}$ is typically calibrated or a priori considered to be very low, posterior estimates in Adolfson, Laseen, Lindé, and Villani (2007) range from 0.1 to above 0.4. Given the uncertainty around this parameter, we adopt a uniform prior on the interval 0.0001 to 0.4 .

In new Keynesian versions of our model that incorporate both monetary and fiscal policies, two distinct regions of the parameter subspace deliver unique bounded rational expectations equilibriaan active monetary, passive fiscal policy $(\mathrm{AM} / \mathrm{PF})$ regime or a passive monetary, active fiscal (PM/AF) policy regime. ${ }^{5}$ Policy parameter priors in the benchmark specification are chosen to impose the $\mathrm{AM} / \mathrm{PF}$ regime: the monetary authority raises the interest rate more than one-for-one with inflation to offset inflation deviations from target; the fiscal authority adjusts expenditures and tax rates to stabilize debt. The priors do assign a small, non-zero density outside the determinacy region of the parameter space. However, we restrict the parameter space to the subspace in which the log-linearized model has a unique bounded rational expectations solution by discarding draws from the indeterminacy region.

Section 5.2 reports robustness checks in which the distributions of table 2 are replaced with uniform distributions. Section 6 studies how multipliers change when policies reside in the PM/AF regime. We take 5,000 draws from our priors and calculate the resulting government spending multipliers from the prior distributions.

\footnotetext{
${ }^{5}$ An active authority is defined as an authority who is not constrained by current budgetary conditions and freely chooses the decision rule it wants. A passive authority is constrained by the consumers' and firms' optimizations and by the actions of the active authority. Thus, the passive authority must guarantee that current budgetary conditions are satisfied and, in particular, that the intertemporal government budget constraint holds. See Leeper (1991), Sims (1994), Cochrane (1998), and Woodford (2003) for more discussion.
} 


\begin{tabular}{lllll}
\hline Parameter & \multicolumn{5}{c}{ Prior } \\
\hline \multicolumn{1}{l}{ Preference and HHs } & func. & mean & std. & $90 \%$ int. \\
$\gamma$, risk aversion & & & & \\
$\xi$, inverse Frisch labor elast. & $\mathrm{N}^{+}$ & 2 & 0.6 & {$[1,3]$} \\
$\theta$, habit formation & $\mathrm{N}^{+}$ & 2 & 0.6 & {$[1,3]$} \\
$\mu$, fraction of non-savers & $\mathrm{B}$ & 0.5 & 0.2 & {$[0.17,0.83]$} \\
& $\mathrm{B}$ & 0.3 & 0.1 & {$[0.14,0.48]$}
\end{tabular}

\section{Frictions}

$\psi$, capital utilization

$s$, investment adj. cost

B $\quad 0.6 \quad 0.15 \quad[0.35,0.85]$

$\omega_{p}$, domestic price stickiness

$\mathrm{N} \quad 6 \quad 1.5 \quad[3.5,8.5]$

$\omega_{p x}$, foreign price stickiness

B $\quad 0.5 \quad 0.1 \quad[0.34,0.66]$

$\omega_{w}$, wage stickiness

B $\quad 0.5 \quad 0.1 \quad[0.34,0.66]$

$\eta_{p}$, price mark-up

B $\quad 0.5 \quad 0.1 \quad[0.34,0.66]$

$\eta_{w}$, wage mark-up

$\mathrm{N}^{+} \quad 0.15 \quad 0.02 \quad[0.12,0.18]$

$\chi^{p}$, domestic price partial indexation

$\mathrm{N}^{+}$

$0.15 \quad 0.02$

$[0.12,0.18]$

$\chi^{p x}$, foreign price partial indexation

B $\quad 0.5 \quad 0.15 \quad[0.25,0.75]$

$\chi^{w}$, wage partial indexation

$\begin{array}{lll}\text { B } & 0.5 & 0.15\end{array}$

$[0.25,0.75]$

B $\quad 0.5 \quad 0.15 \quad[0.25,0.75]$

\section{Openness}

$\nu^{C}$, consumption import share

$\mathrm{N}^{+}$

$\begin{array}{ll}0.25 & 0.07\end{array}$

$[0.13,0.37]$

$\nu^{I}$, investment import share

$\mathrm{N}^{+}$

$0.25 \quad 0.07$

$\mu^{C}$, cons. substitution among brands

$\mathrm{N}^{+}$

1.5

$[0.13,0.37]$

$\mu^{I}$, invest. substitution among brands

$\mathrm{N}^{+}$

1.5

0.25

$[1.1,1.9]$

$\gamma_{f}$, risk premium

U $\quad 0.2$

0.25

$[1.1,1.9]$

$0.12 \quad[0.02,0.38]$

\section{Monetary policy}

$\phi_{\pi}$, interest rate resp. to inflation

$\phi_{y}$, interest rate resp. to output

$\begin{array}{llll}\mathrm{N} & 1.5 & 0.25 & {[1.1,1.8]} \\ \mathrm{N}^{+} & 0.15 & 0.05 & {[0.07,0.23]} \\ \mathrm{B} & 0.7 & 0.2 & {[0.32,0.96]}\end{array}$

$\rho_{r}$, lagged interest rate resp.

\section{Fiscal policy}

$\gamma_{G}$, govt consumption resp. to debt $\quad \mathrm{N}^{+} \quad 0.2 \quad 0.05 \quad[0.12,0.28]$

$\gamma_{K}$, capital tax resp. to debt $\quad \mathrm{N}^{+} \quad 0.2 \quad 0.05 \quad[0.12,0.28]$

$\gamma_{L}$, labor tax resp. to debt $\quad \mathrm{N}^{+} \quad 0.2 \quad 0.05 \quad[0.12,0.28]$

$\gamma_{Z S}$, saver transfers resp. to debt $\quad \mathrm{N}^{+} \quad 0.2 \quad 0.05 \quad[0.12,0.28]$

$\gamma_{Z N}$, nonsaver transfers resp. to debt $\quad \mathrm{N}^{+} \quad 0.2 \quad 0.05 \quad[0.12,0.28]$

$\begin{array}{lllll}\rho_{G} \text {, lagged govt cons resp. } & \mathrm{B} & 0.7 & 0.2 & {[0.32,0.96]}\end{array}$

$\rho_{K}$, lagged capital tax resp. $\quad$ B $\quad 0.7 \quad 0.2 \quad[0.32,0.96]$

$\rho_{L}$, lagged labor tax resp. $\quad$ B $\quad 0.7 \quad 0.2 \quad[0.32,0.96]$

$\rho_{C}$, lagged cons tax resp. $\quad$ B $\quad 0.7 \quad 0.2 \quad[0.32,0.96]$

$\rho_{Z S}$, lagged saver transfers resp. $\quad$ B $\quad 0.7 \quad 0.2 \quad[0.32,0.96]$

$\rho_{Z N}$, lagged nonsaver transfers resp. $\quad \mathrm{B} \quad 0.7 \quad 0.2 \quad[0.32,0.96]$

Table 2: Prior distributions. 

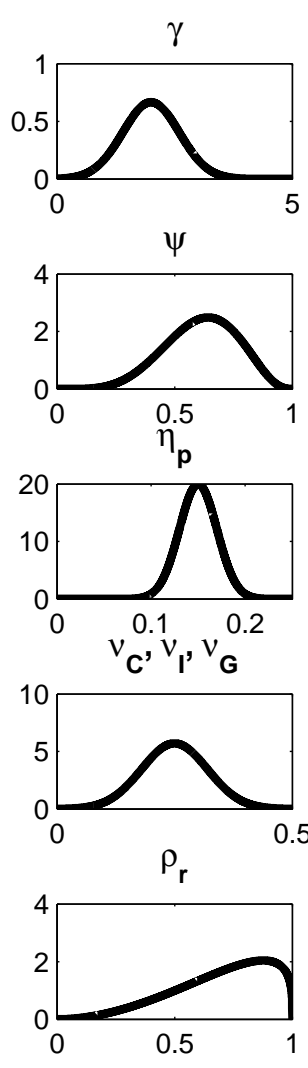

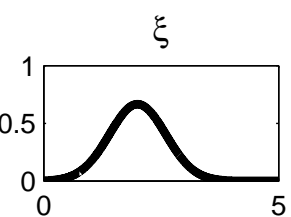

s
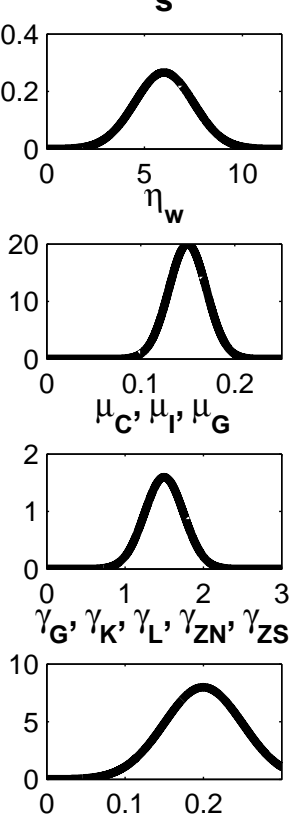
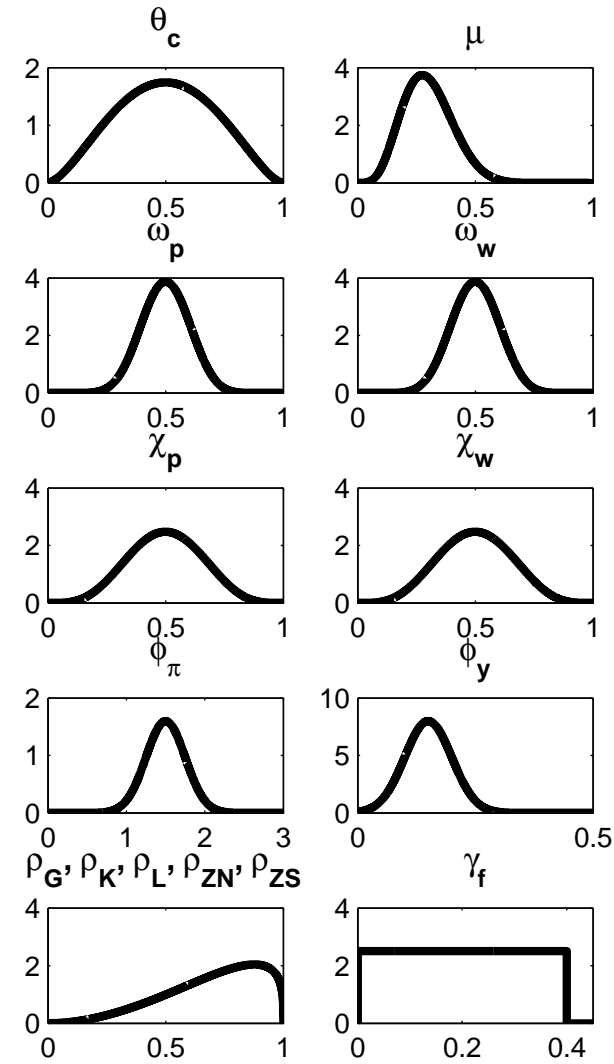

Figure 1: Prior distributions for parameters.

\section{Fiscal Policy Multipliers}

Present-value multipliers, which embody the full dynamics associated with exogenous fiscal actions and properly discount future macroeconomic effects, constitute our vector of interest. The present value of additional output over a $k$-period horizon produced by an exogenous change in the present value of government spending is

$$
\text { Present Value Multiplier }(k)=\frac{E_{t} \sum_{t=0}^{k}\left(\prod_{i=0}^{k} R_{t+i}^{-1}\right) \Delta Y_{t+k}}{E_{t} \sum_{t=0}^{k}\left(\prod_{i=0}^{k} R_{t+i}^{-1}\right) \Delta G_{t+k}}
$$

At $k=0$ the present-value multiplier equals the impact multiplier. To compare multipliers across models, we focus on prior predictive $p$-values. $P$-values are the probability of observing a multiplier $\omega(\theta)$ greater than a particular value in repeated sampling from the model and prior. Table 3 compares multiplier $p$-values at various horizons across the five model specifications. ${ }^{6}$ The top panel of table 3 reports the probability that present-value multipliers for output exceed unity at various horizons. Middle and lower panels report the probabilities that multipliers for consumption and investment, respectively, are positive at various horizons. These particular probabilities address the key issues in the multiplier debate.

Although $p$-values allow easy comparisons across models, they do not summarize the entire prior

\footnotetext{
${ }^{6}$ We approximate the infinite horizon by calculating the present value multipliers over 200 quarters.
} 
distribution. Figure 2 reveals the prior distribution through the median and 90-percent intervals for present-value government spending multipliers for output and consumption at various horizons for models 2, 3, and 4. Consumption multipliers are also decomposed into dynamic Hicksian wealth and substitution effects, following King (1991) and Baxter (1995).

4.1 Hicksian Decomposition To calculate the dynamic Hicksian wealth and substitution effects, we first calculate the discounted lifetime utility associated with the initial steady-state allocations (barred variables): ${ }^{7}$

$$
\bar{U}=\frac{1}{1-\beta}\left[\frac{(\bar{C}-\theta \bar{C})^{1-\gamma}}{1-\gamma}-\frac{\bar{L}^{1+\xi}}{1+\xi}\right]
$$

Let the paths of consumption and labor following a one-percent government spending increase be denoted by $\left\{\hat{C}_{t}, \hat{L}_{t}\right\}_{t=0}^{\infty}$ with associated prices $\left\{\left(1-\tau_{t}^{l}\right) w_{t},\left(1-\tau_{t}^{k}\right) R_{t}^{k}, P_{t}^{C}\left(1+\tau_{t}^{c}\right), P_{t}^{I}, R_{t}\right\}_{t=0}^{\infty}$ and define $U^{\text {total }}$ as the present discounted utility associated with this path, approximated as

$$
U^{\text {total }}=\frac{1}{\bar{U}} \sum_{t=0}^{\infty} \beta^{t}\left[\bar{C}^{1-\gamma}(1-\theta)^{-\gamma} \hat{C}_{t}-\theta \bar{C}^{1-\gamma}(1-\theta)^{-\gamma} \hat{C}_{t-1}-\bar{L}^{1+\xi} \hat{L}_{t}\right]
$$

We then compute the wealth effect as the constant values of consumption and labor such that, at the initial steady-state prices, present discounted utility equals $U^{\text {total}}$; that is, the constant values of consumption and labor that satisfy ${ }^{8}$

$$
\begin{aligned}
U^{\text {total }} & =\frac{1}{(1-\beta) \bar{U}}\left[\bar{C}^{1-\gamma}(1-\theta)^{1-\gamma} \hat{C}^{\text {wealth }}-\bar{L}^{1+\xi} \hat{L}^{\text {wealth }}\right] \\
0 & =\xi \hat{L}^{\text {wealth }}-\gamma \hat{C}^{\text {wealth }}
\end{aligned}
$$

The consumption substitution effect is then $\hat{C}_{t}^{s u b}=\hat{C}_{t}-\hat{C}^{\text {wealth }}$. The substitution effect captures the total value of consumption associated with the prices $\left\{\left(1-\tau_{t}^{l}\right) w_{t},\left(1-\tau_{t}^{k}\right) R_{t}^{k}, P_{t}^{C}(1+\right.$ $\left.\left.\tau_{t}^{c}\right), P_{t}^{I}, R_{t}\right\}_{t=0}^{\infty}$ and the initial steady state lifetime utility $\bar{U}$.

Wealth and substitution consumption multipliers come from

$$
\begin{gathered}
\text { Wealth Present Value Multiplier }(k)=\frac{E_{t} \sum_{t=0}^{k}\left(\prod_{i=0}^{j} \bar{R}^{-1}\right) \Delta C^{\text {wealth }}}{E_{t} \sum_{t=0}^{k}\left(\prod_{i=0}^{j} \bar{R}^{-1}\right) \Delta G_{t+j}} \\
\text { Substitution Present Value Multiplier }(k)=\frac{E_{t} \sum_{t=0}^{k}\left(\prod_{i=0}^{j} R_{t+i}^{-1}\right) \Delta C_{t+j}^{s u b}}{E_{t} \sum_{t=0}^{k}\left(\prod_{i=0}^{j} R_{t+i}^{-1}\right) \Delta G_{t+j}}
\end{gathered}
$$

\footnotetext{
${ }^{7}$ For models with two agents, we calculate the lifetime utility for each agent.

${ }^{8}$ For models with sticky wages, we solve a similar set of equations for savers. In this case, we find the constant levels of consumption and wages that satisfy the present value utility constraint, at steady-state labor, and the savers' first-order condition for real wages.
} 
4.2 Results We start by examining the basic real business cycle model with flexible prices and complete asset markets (model 1 in table 3). This model is similar to Baxter and King (1993) and Monacelli and Perotti (2008), with the addition of distortionary fiscal financing, as in Leeper, Plante, and Traum (2010). It is impossible for this model to generate output multipliers greater than one or to produce positive consumption multipliers at any horizon. An unexpected increase in government expenditures creates a negative wealth effect, as taxes are expected to increase in the future to finance the new spending. Agents decrease consumption and work more. These wealth effects are reinforced by negative substitution effects. Real wages decrease with the increase in work efforts and the rental cost of capital increases with the rising marginal product of capital. Consumption and investment are very likely to decrease. These declines in private demand offset most of the increased public demand, causing output to increase by less than the increase in government consumption.
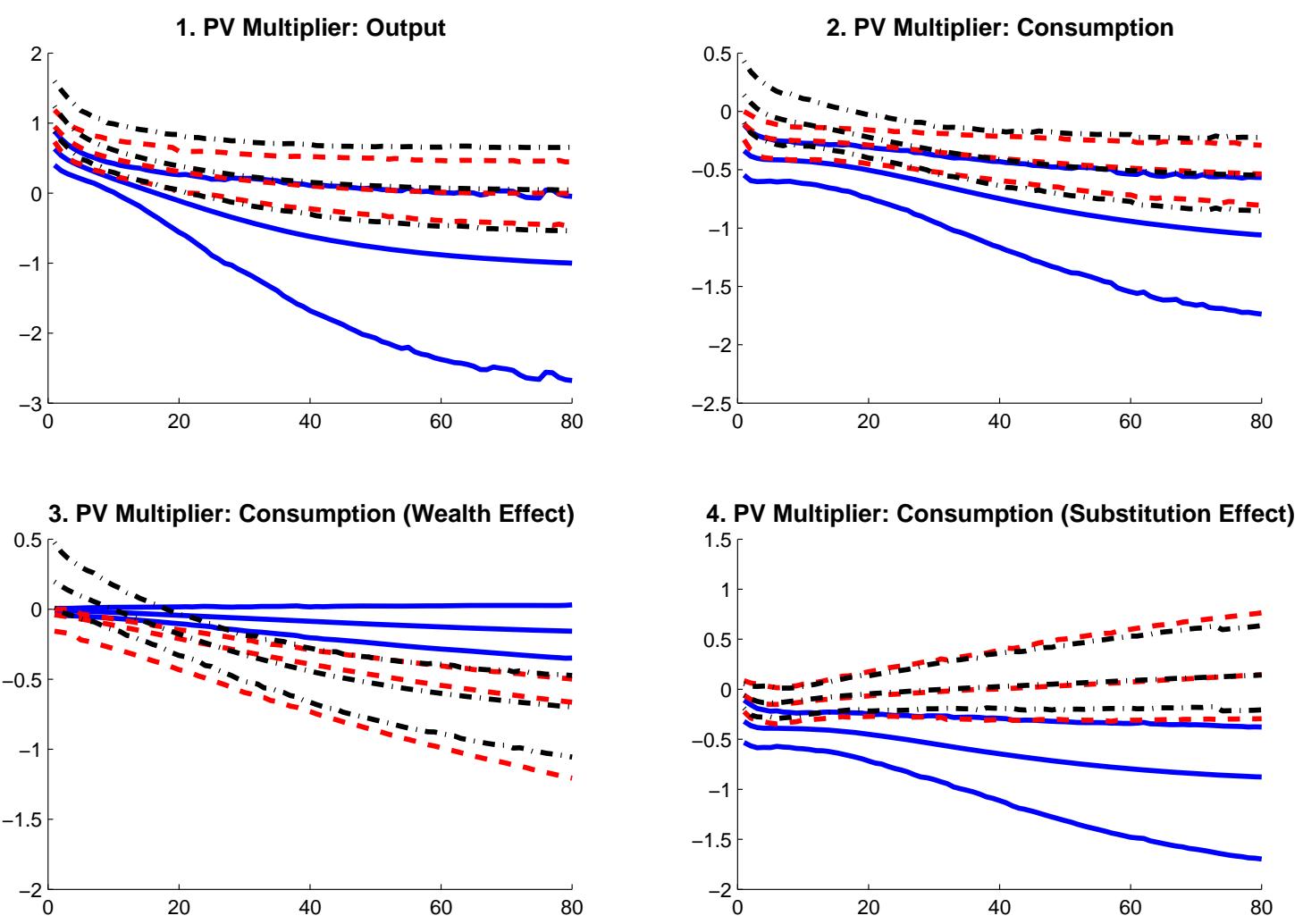

Figure 2: Models 2-4: Present-value government spending multipliers for output and consumption at various horizons, 90-percent probability bands. Consumption multipliers are decomposed into components due to wealth and substitution effects. Solid lines: Model 2, RBC model with real frictions. Dashed lines: Model 3, new Keynesian model with sticky prices and wages. Dotteddashed lines: Model 4, new Keynesian model with non-savers.

There is a small probability $(<0.01)$ that investment will increase at most horizons. This is the only result consistent across all model specifications. Any possibility of higher investment 


\begin{tabular}{|c|c|c|c|c|c|}
\hline \multicolumn{6}{|c|}{$\operatorname{Prob}\left(P V \frac{\Delta Y}{\Delta G}>1\right)$} \\
\hline & Impact & 4 quart. & 10 quart. & 25 quart. & $\infty$ \\
\hline Model 1: Basic RBC & 0.00 & 0.00 & 0.00 & 0.00 & 0.00 \\
\hline Model 2: RBC Real Frictions & 0.01 & 0.00 & 0.00 & 0.00 & $<0.01$ \\
\hline Model 3: NK Sticky Price \& Wage & 0.35 & 0.01 & $<0.01$ & 0.00 & 0.00 \\
\hline Model 4: NK Nonsavers & 0.88 & 0.32 & 0.07 & 0.02 & 0.01 \\
\hline Model 5: NK Open Economy & 0.81 & 0.27 & 0.05 & 0.01 & 0.01 \\
\hline \multicolumn{6}{|c|}{$\operatorname{Prob}\left(P V \frac{\Delta C}{\Delta G}>0\right)$} \\
\hline & Impact & 4 quart. & 10 quart. & 25 quart. & $\infty$ \\
\hline Model 1: Basic RBC & 0.00 & 0.00 & 0.00 & 0.00 & 0.00 \\
\hline Model 2: RBC Real Frictions & 0.00 & 0.00 & 0.00 & 0.00 & $<0.01$ \\
\hline Model 3: NK Sticky Price \& Wage & $<0.01$ & 0.00 & 0.00 & 0.00 & 0.00 \\
\hline Model 4: NK Nonsavers & 0.84 & 0.46 & 0.18 & 0.02 & 0.01 \\
\hline Model 5: NK Open Economy & 0.82 & 0.48 & 0.23 & 0.02 & $<0.01$ \\
\hline \multicolumn{6}{|c|}{$\operatorname{Prob}\left(P V \frac{\Delta I}{\Delta G}>0\right)$} \\
\hline & Impact & 4 quart. & 10 quart. & 25 quart. & $\infty$ \\
\hline Model 1: Basic RBC & $<0.01$ & $<0.01$ & $<0.01$ & $<0.01$ & 0.00 \\
\hline Model 2: RBC Real Frictions & $<0.01$ & $<0.01$ & $<0.01$ & $<0.01$ & $<0.01$ \\
\hline Model 3: NK Sticky Price \& Wage & $<0.01$ & $<0.01$ & $<0.01$ & $<0.01$ & 0.00 \\
\hline Model 4: NK Nonsavers & $<0.01$ & $<0.01$ & $<0.01$ & $<0.01$ & 0.01 \\
\hline Model 5: NK Open Economy & $<0.01$ & $<0.01$ & $<0.01$ & $<0.01$ & 0.01 \\
\hline
\end{tabular}

Table 3: Government spending multiplier probabilities implied by prior predictive analysis with informative priors. 
stems from a subset of very high draws for $\rho_{G}$, the serial correlation of government spending. As $\rho_{G}$ approaches one, agents view an exogenous change in government spending as approximately permanent. Permanent increases in government consumption encourage households to save more, raising investment, a pattern that is robust across model specifications. In the absence of large value of $\rho_{G}$, investment would never rise across models.

Model 2 introduces real frictions (habit formation, investment adjustment costs, and capacity utilization), which substantially affect the short- and long-run multipliers [solid lines in figure 2]. Now the possible range of multipliers is much larger, especially on the downside. Intuitively, after government spending rises temporarily, agents are less willing to decrease consumption quickly with habit formation because changes in consumption are costly and consumption must return to its steady-state value in the long-run. This implies a more negative consumption multiplier on impact.

Similarly, investment adjustment costs and capacity utilization costs deter large swings in investment, decreasing the negative investment multipliers. ${ }^{9}$ Although the multipliers change quantitatively relative to model 1 , the policy implications from the two models are virtually the same, as the probabilities reported in table 3 are unaltered.

Model 3 introduces sticky prices and sticky wages, which increase multipliers at all horizons, as Woodford (2011) shows analytically. Greater price stickiness means that more firms respond to higher government spending by increasing production rather than prices, so markups respond more strongly. In the long run, the 90-percent interval for present value output multipliers includes positive values [dashed lines of panel 1 of figure 2]. RBC models cannot produce these positive longrun multipliers; nominal rigidities, as in new Keynesian-style models, are necessary for spending increases to persistently raise output.

Wage rigidities have a strong effect on consumption multipliers. Sticky wages can reverse the sign of the substitution effect on consumption [compare dashed to solid lines in figure 2]. Positive substitution effects can arise because real wages may increase to offset other price effects that generate negative substitution effects.

Non-savers (model 4) raise fiscal multipliers substantially. The fraction of non-savers is the most influential parameter for the output multiplier, as variations in this parameter are necessary to get median impact output multipliers greater than one (the dotted-dashed lines of panel 1 of figure 2). Unlike savers, non-savers ignore the wealth effects of future taxes, so they increase their consumption when government consumption rises. Non-savers consume their entire income each period and do not take into account the negative wealth effects that savers consider, reducing the negative wealth effect on consumption [panel 3]. If wages are sticky, so that real wages increase on impact, then non-saver consumption increases as well. With enough non-savers in the economy, the increase in non-saver consumption can be large enough to cause total consumption to increase on impact (the dotted-dashed lines of panel 2 of figure 2), leading to larger output multipliers as well.

\footnotetext{
${ }^{9}$ See Monacelli and Perotti (2008) for a more detailed examination of the effect of habit formation and investment adjustment costs on multipliers in a simple RBC model.
} 
The open-economy framework (model 5), reduces the probabilities both of output multipliers being greater than one and of positive consumption multipliers. In the open economy, increases in government expenditures induce substitution away from domestically-produced goods towards imported goods. Higher demand raises production costs, increasing prices of domestic goods and of domestic goods in the foreign market. Domestic households, in turn, reduce their demand for domestic production and increase demand for imports. Foreigners also reduce their demand for domestic exports. This import-substitution effect makes output multipliers smaller on average than they are in the closed economy.

Model 5 imposes financial autarky, which tends to raise short-run multipliers in an open economy. Because trade in goods must be balanced each period, the import substitution effect is smaller, with nominal imports constrained to equal exports. Multipliers are smaller with international financial integration. Financial integration allows the domestic economy to run trade deficits and consume more imports, causing output to decrease more in the short run. Multipliers also are smaller when government spending is a traded good, as part of the increase in government spending goes directly to the foreign country. ${ }^{10}$ Impact consumption multipliers decrease by half in an open economy with a traded government spending good, as compared to the closed-economy setting. These results help explain some of the differences in multipliers between IMF10/73 and Cwik and Wieland (2011), as the open-economy models in those meta-studies make different assumptions about the nature of openness.

4.3 Summary Looking across the specifications, a few observations emerge. First, real and nominal frictions, non-savers, and open economy considerations quantitatively alter multipliers. Nominal rigidities and non-savers are critical to generate positive long-run output multipliers. Although the broadest model can produce output multipliers greater than one, it is difficult for that model to produce substantially large multipliers. A closed economy with non-savers produces the largest impact output multipliers, with a 90 -percent interval from 0.84 to 1.75 . This suggests that it is hard, even for this model, to generate multipliers greater than 2.

\section{Digging Deeper}

We now turn to more detailed analyses. This section isolates the contributions of individual parameters to multipliers and examines the influence of priors.

5.1 Individual Parameter Contributions So far the analysis has largely ignored the effect a particular parameter has on present-value multipliers. To determine how much individual parameters affect the multipliers, we calculate a measure of root mean square deviation (RMSD) for each parameter. For each draw of parameters, $\tilde{\theta}=\left[\begin{array}{lll}\tilde{\theta}_{1} & \ldots & \tilde{\theta}_{n}\end{array}\right]^{\prime}$ from $p(\theta)$, we calculate multipliers $\tilde{\omega}(\tilde{\theta})$. Redefine the parameter vector when the $i^{\text {th }}$ parameter is fixed at its prior mean, $E\left[\theta_{i}\right]$. Denote that vector by $\left.\tilde{\theta}^{i}=\left[\begin{array}{lllll}\tilde{\theta}_{1} & \ldots & E\left[\theta_{i}\right.\end{array}\right] \ldots \tilde{\theta}_{n}\right]^{\prime}$ and calculate the multipliers, $\tilde{\omega}^{i}\left(\tilde{\theta}^{i}\right)$. Repeat this for each

\footnotetext{
${ }^{10}$ Results for these cases are reported in the appendix.
} 
$i=1,2, \ldots n$. The RMSD is the root mean square deviation between the two multipliers $\tilde{\omega}(\tilde{\theta})$ and $\tilde{\omega}^{i}\left(\tilde{\theta}^{i}\right)$ : it measures how much the multiplier varies on average due to parameter $i$. The RMSD is largest for the parameters that are most influential for the multiplier. Tables 4 and 5 report the fraction of total RMSDs of multipliers attributable to each parameter in the open economy new Keynesian model (model 5) at various horizons.

The fraction of non-savers, $\mu$, is the most influential parameter on the output and consumption impact multipliers. Non-savers consume their entire income each period and do not take into account the negative wealth effects that savers consider. If real wages increase on impact, then non-saver consumption and, therefore, output increase as well. ${ }^{11}$ This fraction accounts for 19 percent of the output multiplier (table 4) and 28 percent of the consumption multiplier (table 5) on impact. The fraction of non-savers is not particularly important for long-run multipliers.

Persistence of the government spending process, governed by $\rho_{G}$, is the second most important parameter for impact multipliers. The greater the persistence, the larger are the negative wealth effects because larger increases in taxes are required to finance the increase in the government spending process. Persistence accounts for 19 and 16 percent of the output and consumption multipliers on impact. The influence of $\rho_{G}$ grows over time to explain about 30 percent of multipliers in the long run.

Habit formation, $\theta$, and capacity utilization cost, $\psi$, parameters are also important for impact multipliers. As habit formation increases, households value consumption smoothing more, which dampens the variation in consumption (and thus output) over time. Capacity utilization costs matter for output multipliers, as our measure of output depends directly on the utilization rate.

Impact multipliers are increasing with risk aversion $\gamma$, as Monacelli and Perotti (2008) note. Higher risk aversion (or smaller intertemporal elasticity of substitution), makes households less willing to postpone consumption into the future. This decreases the variation of consumption and output following government spending changes. Consumption multipliers are substantially influenced by the risk aversion parameter in the short and long runs [table 5].

Monetary policy also influences multipliers. As Woodford (2011) and IMF10/73 note, the more accommodative monetary policy is, the larger the multipliers are. Multipliers are decreasing in $\phi_{\pi}$ and $\phi_{y}$ and increasing in $\rho_{r}$. Variation in $\rho_{r}$ is particularly important, accounting for about 10 percent of impact multipliers. Changes in $\rho_{r}$ directly affect the persistence of real interest rates following a government spending expansion. Real rates, in turn, have important impacts on present-value calculations.

5.2 Influence OF Priors Our priors are informative and influence the distribution of multipliers implied by the model specifications. To show the sensitivity of multipliers to the priors, we calculate multipliers conditional on diffuse, uniform priors [table 6]. Table 7 reports multiplier $p$-values at various horizons for the model specifications when the uniform priors are employed.

\footnotetext{
${ }^{11}$ As noted in Galí, López-Salido, and Vallés (2007), non-savers are vital for multipliers when coupled with nominal wage rigidities. The appendix details how non-savers have no substantial impact on multipliers when the labor market is perfectly competitive.
} 


\begin{tabular}{|c|c|c|c|c|c|}
\hline \multirow[t]{2}{*}{ Parameter } & \multicolumn{5}{|c|}{ RMSD $P V \frac{\Delta Y}{\Delta G}$} \\
\hline & Impact & 4 qtrs. & 10 qtrs. & 25 qtrs. & $\infty$ \\
\hline \multicolumn{6}{|l|}{ Preference and HHs } \\
\hline$\gamma$, risk aversion & 0.05 & 0.07 & 0.05 & 0.04 & 0.04 \\
\hline$\xi$, inverse Frisch labor elast. & 0.02 & 0.04 & 0.04 & 0.05 & 0.06 \\
\hline$\theta$, habit formation & 0.08 & 0.07 & 0.03 & 0.03 & 0.02 \\
\hline$\mu$, fraction of non-savers & 0.19 & 0.13 & 0.08 & 0.05 & 0.04 \\
\hline \multicolumn{6}{|l|}{ Frictions and Production } \\
\hline$\psi$, capital utilization & 0.15 & 0.12 & 0.08 & 0.05 & 0.04 \\
\hline$s$, investment adjust. cost & 0.03 & 0.05 & 0.05 & 0.03 & 0.03 \\
\hline$\omega_{p}$, domestic price stickiness & 0.02 & 0.01 & 0.01 & 0.01 & 0.00 \\
\hline$\omega_{p x}$, foreign price stickiness & 0.01 & 0.00 & 0.00 & 0.00 & 0.00 \\
\hline$\omega_{w}$, wage stickiness & 0.02 & 0.05 & 0.06 & 0.06 & 0.06 \\
\hline$\eta_{p}$, price mark-up & 0.02 & 0.01 & 0.01 & 0.01 & 0.01 \\
\hline$\eta_{w}$, wage mark-up & 0.00 & 0.01 & 0.01 & 0.01 & 0.01 \\
\hline$\chi^{p}$, domestic price partial indexation & 0.01 & 0.00 & 0.00 & 0.00 & 0.00 \\
\hline$\chi^{p x}$, foreign price partial indexation & 0.00 & 0.00 & 0.00 & 0.00 & 0.00 \\
\hline$\chi^{w}$, wage partial indexation & 0.01 & 0.03 & 0.04 & 0.03 & 0.03 \\
\hline \multicolumn{6}{|l|}{ Openness } \\
\hline$\nu^{C}$, cons. import share & 0.02 & 0.01 & 0.01 & 0.00 & 0.01 \\
\hline$\nu^{I}$, inv. import share & 0.01 & 0.00 & 0.01 & 0.01 & 0.01 \\
\hline$\mu^{C}$, cons. substitution among brands & 0.00 & 0.00 & 0.01 & 0.01 & 0.01 \\
\hline$\mu^{I}$, inv. substitution among brands & 0.00 & 0.00 & 0.00 & 0.00 & 0.00 \\
\hline \multicolumn{6}{|l|}{ Monetary Policy } \\
\hline$\phi_{\pi}$, interest rate resp. to inflation & 0.04 & 0.04 & 0.04 & 0.04 & 0.05 \\
\hline$\phi_{y}$, interest rate resp. to output & 0.02 & 0.03 & 0.04 & 0.03 & 0.02 \\
\hline$\rho_{r}$, lagged interest rate resp. & 0.10 & 0.07 & 0.09 & 0.08 & 0.07 \\
\hline \multicolumn{6}{|l|}{ Fiscal Policy } \\
\hline$\gamma_{G}$, govt consumption resp. to debt & 0.00 & 0.00 & 0.01 & 0.01 & 0.02 \\
\hline$\gamma_{K}$, capital tax resp. to debt & 0.00 & 0.00 & 0.01 & 0.03 & 0.02 \\
\hline$\gamma_{L}$, labor tax resp. to debt & 0.00 & 0.00 & 0.01 & 0.02 & 0.01 \\
\hline$\gamma_{Z S}$, saver transfer resp. to debt & 0.00 & 0.00 & 0.00 & 0.01 & 0.04 \\
\hline$\gamma_{Z N}$, nonsaver transfer resp. to debt & 0.00 & 0.00 & 0.00 & 0.00 & 0.01 \\
\hline$\rho_{G}$, lagged govt cons resp. & 0.19 & 0.22 & 0.28 & 0.29 & 0.30 \\
\hline$\rho_{K}$, lagged capital tax resp. & 0.00 & 0.00 & 0.02 & 0.03 & 0.01 \\
\hline$\rho_{L}$, lagged labor tax resp. & 0.00 & 0.01 & 0.02 & 0.03 & 0.01 \\
\hline$\rho_{C}$, lagged cons tax resp. & 0.00 & 0.00 & 0.00 & 0.00 & 0.00 \\
\hline$\rho_{Z S}$, lagged saver transfer resp. & 0.00 & 0.00 & 0.00 & 0.01 & 0.02 \\
\hline$\rho_{Z N}$, lagged nonsaver transfer resp. & 0.00 & 0.01 & 0.00 & 0.01 & 0.01 \\
\hline
\end{tabular}

Table 4: RMSDs for model 5, New Keynesian open economy model. Columns may not sum to 1.0 due to rounding. 


\begin{tabular}{|c|c|c|c|c|c|}
\hline \multirow[t]{2}{*}{ Parameter } & \multicolumn{5}{|c|}{ RMSD $P V \frac{\Delta C}{\Delta G}$} \\
\hline & Impact & 4 qtrs. & 10 qtrs. & 25 qtrs. & $\infty$ \\
\hline \multicolumn{6}{|l|}{ Preference and HHs } \\
\hline$\gamma$, risk aversion & 0.09 & 0.13 & 0.12 & 0.09 & 0.08 \\
\hline$\xi$, inverse Frisch labor elast. & 0.01 & 0.02 & 0.03 & 0.04 & 0.06 \\
\hline$\theta$, habit formation & 0.12 & 0.11 & 0.05 & 0.02 & 0.02 \\
\hline$\mu$, fraction of non-savers & 0.28 & 0.23 & 0.18 & 0.07 & 0.04 \\
\hline \multicolumn{6}{|l|}{ Frictions and Production } \\
\hline$\psi$, capital utilization & 0.03 & 0.04 & 0.03 & 0.02 & 0.01 \\
\hline$s$, investment adjust. cost & 0.01 & 0.02 & 0.02 & 0.01 & 0.02 \\
\hline$\omega_{p}$, domestic price stickiness & 0.02 & 0.01 & 0.01 & 0.01 & 0.01 \\
\hline$\omega_{p x}$, foreign price stickiness & 0.00 & 0.00 & 0.00 & 0.00 & 0.00 \\
\hline$\omega_{w}$, wage stickiness & 0.01 & 0.04 & 0.05 & 0.06 & 0.06 \\
\hline$\eta_{p}$, price mark-up & 0.02 & 0.02 & 0.01 & 0.01 & 0.02 \\
\hline$\eta_{w}$, wage mark-up & 0.00 & 0.01 & 0.01 & 0.01 & 0.01 \\
\hline$\chi^{p}$, domestic price partial indexation & 0.01 & 0.00 & 0.00 & 0.00 & 0.00 \\
\hline$\chi^{p x}$, foreign price partial indexation & 0.00 & 0.00 & 0.00 & 0.00 & 0.00 \\
\hline$\chi^{w}$, wage partial indexation & 0.01 & 0.02 & 0.03 & 0.03 & 0.03 \\
\hline \multicolumn{6}{|l|}{ Openness } \\
\hline$\nu^{C}$, cons. import share & 0.01 & 0.02 & 0.02 & 0.03 & 0.04 \\
\hline$\nu^{I}$, inv. import share & 0.00 & 0.00 & 0.01 & 0.01 & 0.01 \\
\hline$\mu^{C}$, cons. substitution among brands & 0.00 & 0.01 & 0.01 & 0.02 & 0.03 \\
\hline$\mu^{I}$, inv. substitution among brands & 0.00 & 0.00 & 0.00 & 0.01 & 0.01 \\
\hline \multicolumn{6}{|l|}{ Monetary Policy } \\
\hline$\phi_{\pi}$, interest rate resp. to inflation & 0.04 & 0.04 & 0.04 & 0.05 & 0.05 \\
\hline$\phi_{y}$, interest rate resp. to output & 0.02 & 0.03 & 0.03 & 0.04 & 0.03 \\
\hline$\rho_{r}$, lagged interest rate resp. & 0.12 & 0.07 & 0.06 & 0.06 & 0.06 \\
\hline \multicolumn{6}{|l|}{ Fiscal Policy } \\
\hline$\gamma_{G}$, govt consumption resp. to debt & 0.00 & 0.00 & 0.01 & 0.01 & 0.02 \\
\hline$\gamma_{K}$, capital tax resp. to debt & 0.01 & 0.01 & 0.01 & 0.01 & 0.01 \\
\hline$\gamma_{L}$, labor tax resp. to debt & 0.00 & 0.00 & 0.02 & 0.05 & 0.03 \\
\hline$\gamma_{Z S}$, saver transfer resp. to debt & 0.01 & 0.01 & 0.01 & 0.01 & 0.03 \\
\hline$\gamma_{Z N}$, nonsaver transfer resp. to debt & 0.00 & 0.00 & 0.01 & 0.03 & 0.01 \\
\hline$\rho_{G}$, lagged govt cons resp. & 0.16 & 0.15 & 0.18 & 0.19 & 0.28 \\
\hline$\rho_{K}$, lagged capital tax resp. & 0.00 & 0.00 & 0.01 & 0.01 & 0.01 \\
\hline$\rho_{L}$, lagged labor tax resp. & 0.00 & 0.01 & 0.04 & 0.06 & 0.02 \\
\hline$\rho_{C}$, lagged cons tax resp. & 0.00 & 0.00 & 0.00 & 0.00 & 0.00 \\
\hline$\rho_{Z S}$, lagged saver transfer resp. & 0.00 & 0.00 & 0.01 & 0.01 & 0.01 \\
\hline$\rho_{Z N}$, lagged nonsaver transfer resp. & 0.00 & 0.01 & 0.02 & 0.04 & 0.00 \\
\hline
\end{tabular}

Table 5: RMSDs for model 5, new Keynesian open economy model. Columns may not sum to 1.0 due to rounding. 
Uniform priors increase the probability of parameter draws from a larger region of the parameter space. This, in turn, allows a larger range of multipliers and increases the probabilities of output multipliers greater than one and of positive consumption and investment multipliers. Comparing the probabilities under the two sets of prior distributions reveals that the prior specification is most informative about multipliers over longer horizons. However, model specifications often still imply tight multiplier ranges, and the general conclusions reported above still hold. It remains difficult to generate positive investment multipliers over any horizon. In addition, nominal rigidities and non-savers remain critical to achieving positive long-run output multipliers.

\section{Alternative Fiscal-Monetary Regimes}

All the work reported above maintains the assumption that monetary policy actively targets inflation. Prior distributions place either minuscule (table 2) or zero (table 6) probability on monetary policy responding less than one-for-one to inflation $\left(\phi_{\pi}<1\right)$. With central banks operating at or near the zero lower bound for nominal interest rates in recent years, it is useful to compute fiscal multipliers in a regime with passive monetary policy and active fiscal policy. Christiano, Eichenbaum, and Rebelo (2011) and Davig and Leeper (2011) both find that this alternative policy regime can produce substantially larger government spending multipliers.

To explore how the multipliers depend on the fiscal-monetary specification, we calculate multipliers conditional on model 5 (the open economy new Keynesian model) in a passive monetary and active fiscal (PM/AF) policy regime. In this specification, the monetary authority raises the interest rate less than one-for-one with inflation deviations from target, and the fiscal authority does not adjust fiscal instruments sufficiently to stabilize debt. To ensure this, we modify our priors by assuming $\phi_{\pi}$ has a uniform distribution on the unit interval, and $\gamma_{g}, \gamma_{k}, \gamma_{l}, \gamma_{z s}$, and $\gamma_{z n}$ have normal distributions with zero means and standard deviations of 0.03. As above, we ensure that each parameter draw delivers a unique bounded rational expectations equilibrium.

Table 8 reports multiplier $p$-values at various horizons conditional on the PM/AF regime. The multiplier probabilities change drastically: it is impossible in the short run for output multipliers to be less than one and for consumption multipliers to be negative [non-uniform prior lines in the table]. In addition, the probability of positive investment multipliers is substantial at all horizons. Figure 3 compares multipliers in the open economy model for the benchmark active monetary/passive fiscal, $\mathrm{AM} / \mathrm{PF}$, (dotted lines) and the alternative PM/AF (solid lines) regimes.

A persistent increase in government consumption raises current and future demand, as well as current and expected inflation. Under passive monetary policy, the monetary authority responds to the increase in inflation less than one-for-one, which allows the real interest rate to fall. Declining real interest rates lower the return to saving, encouraging households to increase consumption and leading to positive substitution effects. Higher private demand, coupled with a lower rental cost of capital, encourages firms to demand more capital and investment rises on impact in most cases.

A uniform prior on all the parameters somewhat attenuates these large government spending impacts. Although output multipliers are still likely to exceed unity and consumption multipliers 


\begin{tabular}{|c|c|c|}
\hline \multirow[t]{2}{*}{ Parameter } & \multicolumn{2}{|r|}{ Prior } \\
\hline & func. & interval \\
\hline \multicolumn{3}{|l|}{$\overline{\text { Preference and } \mathrm{HHs}}$} \\
\hline$\gamma$, risk aversion & $\mathrm{U}$ & {$[0,6]$} \\
\hline$\xi$, inverse Frisch labor elast. & $\mathrm{U}$ & {$[0,6]$} \\
\hline$\theta$, habit formation & $\mathrm{U}$ & {$[0,1]$} \\
\hline$\mu$, fraction of non-savers & $\mathrm{U}$ & {$[0,0.6]$} \\
\hline \multicolumn{3}{|l|}{ Frictions } \\
\hline$\psi$, capital utilization & $\mathrm{U}$ & {$[0,1]$} \\
\hline$s$, investment adj. cost & $\mathrm{U}$ & {$[0,10]$} \\
\hline$\omega_{p}$, domestic price stickiness & $\mathrm{U}$ & {$[0,1]$} \\
\hline$\omega_{p x}$, foreign price stickiness & $\mathrm{U}$ & {$[0,1]$} \\
\hline$\omega_{w}$, wage stickiness & $\mathrm{U}$ & {$[0,1]$} \\
\hline$\eta_{p}$, price mark-up & $\mathrm{U}$ & {$[0,0.5]$} \\
\hline$\eta_{w}$, wage mark-up & $\mathrm{U}$ & {$[0,0.5]$} \\
\hline$\chi^{p}$, domestic price partial indexation & $\mathrm{U}$ & {$[0,1]$} \\
\hline$\chi^{p x}$, foreign price partial indexation & $\mathrm{U}$ & {$[0,1]$} \\
\hline$\chi^{w}$, wage partial indexation & $\mathrm{U}$ & {$[0,1]$} \\
\hline \multicolumn{3}{|l|}{ Openness } \\
\hline$\nu^{C}$, consumption import share & $\mathrm{U}$ & {$[0,1]$} \\
\hline$\nu^{I}$, investment import share & $\mathrm{U}$ & {$[0,1]$} \\
\hline$\mu^{C}$, cons. substitution among brands & $\mathrm{U}$ & {$[1,4]$} \\
\hline$\mu^{I}$, invest. substitution among brands & $\mathrm{U}$ & {$[1,4]$} \\
\hline$\gamma_{f}$, risk premium & $\mathrm{U}$ & {$[0.0001,0.4]$} \\
\hline \multicolumn{3}{|l|}{ Monetary policy } \\
\hline$\phi_{\pi}$, interest rate resp. to inflation & $\mathrm{U}$ & {$[1,4]$} \\
\hline$\phi_{y}$, interest rate resp. to output & $\mathrm{U}$ & {$[0,0.5]$} \\
\hline$\rho_{r}$, lagged interest rate resp. & $\mathrm{U}$ & {$[0,1]$} \\
\hline
\end{tabular}

Fiscal policy

$\gamma_{G}$, govt consumption resp. to debt $\mathrm{U} \quad[0,0.5]$

$\gamma_{K}$, capital tax resp. to debt $\quad \mathrm{U} \quad[0,0.5]$

$\gamma_{L}$, labor tax resp. to debt $\quad \mathrm{U} \quad[0,0.5]$

$\gamma_{Z S}$, saver transfers resp. to debt $\quad \mathrm{U} \quad[0,0.5]$

$\gamma_{Z N}$, nonsaver transfers resp. to debt $\mathrm{U} \quad[0,0.5]$

$\rho_{G}$, lagged govt cons resp. $\quad \mathrm{U} \quad[0,1]$

$\rho_{K}$, lagged capital tax resp. $\quad \mathrm{U} \quad[0,1]$

$\rho_{L}$, lagged labor tax resp. $\quad \mathrm{U} \quad[0,1]$

$\rho_{C}$, lagged cons tax resp. $\quad \mathrm{U} \quad[0,1]$

$\rho_{Z S}$, lagged saver transfers resp. $\quad \mathrm{U} \quad[0,1]$

$\rho_{Z N}$, lagged nonsaver transfers resp. $\quad \mathrm{U} \quad[0,1]$

Table 6: Uniform Prior distributions. 


\begin{tabular}{|c|c|c|c|c|c|}
\hline \multicolumn{6}{|c|}{$\operatorname{Prob}\left(P V \frac{\Delta Y}{\Delta G}>1\right)$} \\
\hline & Impact & 4 quart. & 10 quart. & 25 quart. & $\infty$ \\
\hline Model 1: Basic RBC & 0.00 & 0.00 & 0.00 & 0.00 & 0.00 \\
\hline Model 2: RBC Real Frictions & 0.11 & 0.03 & 0.01 & 0.07 & 0.13 \\
\hline Model 3: NK Sticky Price \& Wage & 0.43 & 0.17 & 0.09 & 0.08 & 0.10 \\
\hline Model 4: NK Nonsavers & 0.76 & 0.46 & 0.26 & 0.20 & 0.20 \\
\hline Model 5: NK Open Economy & 0.69 & 0.42 & 0.24 & 0.19 & 0.19 \\
\hline \multicolumn{6}{|c|}{$\operatorname{Prob}\left(P V \frac{\Delta C}{\Delta G}>0\right)$} \\
\hline & Impact & 4 quart. & 10 quart. & 25 quart. & $\infty$ \\
\hline Model 1: Basic RBC & 0.00 & 0.00 & 0.00 & 0.00 & 0.00 \\
\hline Model 2: RBC Real Frictions & 0.00 & 0.00 & 0.01 & 0.07 & 0.11 \\
\hline Model 3: NK Sticky Price \& Wage & 0.00 & 0.00 & 0.02 & 0.04 & 0.07 \\
\hline Model 4: NK Nonsavers & 0.73 & 0.57 & 0.32 & 0.15 & 0.15 \\
\hline Model 5: NK Open Economy & 0.73 & 0.60 & 0.37 & 0.16 & 0.16 \\
\hline \multicolumn{6}{|c|}{$\operatorname{Prob}\left(P V \frac{\Delta I}{\Delta G}>0\right)$} \\
\hline & Impact & 4 quart. & 10 quart. & 25 quart. & $\infty$ \\
\hline Model 1: Basic RBC & 0.01 & 0.01 & 0.01 & 0.00 & 0.00 \\
\hline Model 2: RBC Real Frictions & 0.01 & 0.01 & 0.03 & 0.06 & 0.11 \\
\hline Model 3: NK Sticky Price \& Wage & 0.00 & 0.02 & 0.05 & 0.07 & 0.09 \\
\hline Model 4: NK Nonsavers & 0.00 & 0.03 & 0.10 & 0.22 & 0.27 \\
\hline Model 5: NK Open Economy & 0.00 & 0.03 & 0.13 & 0.27 & 0.33 \\
\hline
\end{tabular}

Table 7: Government spending multiplier probabilities implied by prior predictive analysis with uniform priors. 


\begin{tabular}{|c|c|c|c|c|c|}
\hline \multicolumn{6}{|c|}{$\operatorname{Prob}\left(P V \frac{\Delta Y}{\Delta G}>1\right)$} \\
\hline & Impact & 4 quart. & 10 quart. & 25 quart. & $\infty$ \\
\hline Non-uniform prior & 1.00 & 1.00 & 0.97 & 0.93 & 0.91 \\
\hline Uniform prior & 0.94 & 0.85 & 0.79 & 0.77 & 0.77 \\
\hline \multicolumn{6}{|c|}{$\operatorname{Prob}\left(P V \frac{\Delta C}{\Delta G}>0\right)$} \\
\hline & Impact & 4 quart. & 10 quart. & 25 quart. & $\infty$ \\
\hline Non-uniform prior & 1.00 & 1.00 & 1.00 & 0.99 & 0.93 \\
\hline Uniform prior & 0.96 & 0.90 & 0.88 & 0.84 & 0.79 \\
\hline \multicolumn{6}{|c|}{$\operatorname{Prob}\left(P V \frac{\Delta I}{\Delta G}>0\right)$} \\
\hline & Impact & 4 quart. & 10 quart. & 25 quart. & $\infty$ \\
\hline Non-uniform prior & 0.73 & 0.53 & 0.45 & 0.44 & 0.47 \\
\hline Uniform prior & 0.31 & 0.30 & 0.35 & 0.41 & 0.45 \\
\hline
\end{tabular}

Table 8: Government spending multiplier probabilities implied by prior predictive analysis for Model 5 (open economy model) with passive monetary-active fiscal policies.

remain likely to be positive, there is now substantial probability mass on negative investment multipliers [uniform prior lines in table].

The results highlight the importance of fiscal-monetary interactions for policy conclusions. Although the results differ substantially from the benchmark policy regime specification, it is important to note that the $\mathrm{PM} / \mathrm{AF}$ specification also imposes a tight multiplier range. But in this case, it is a tight range of large multipliers.

\section{Conclusion}

This paper has shown, through prior predictive analysis, that many model specifications impose a very tight range for the multiplier even before the models are taken to data. Although multipliers vary substantially across various monetary-fiscal policy specifications, conditional on a particular policy regime, a model still imposes a tight range for multipliers. The results raise a warning flag for policymakers who base decisions on the fiscal multipliers from particular calibrated or estimated models. The tight multiplier ranges that models and priors impose before conditioning on data biases results and may shed little light on the size of multipliers in time series data. 

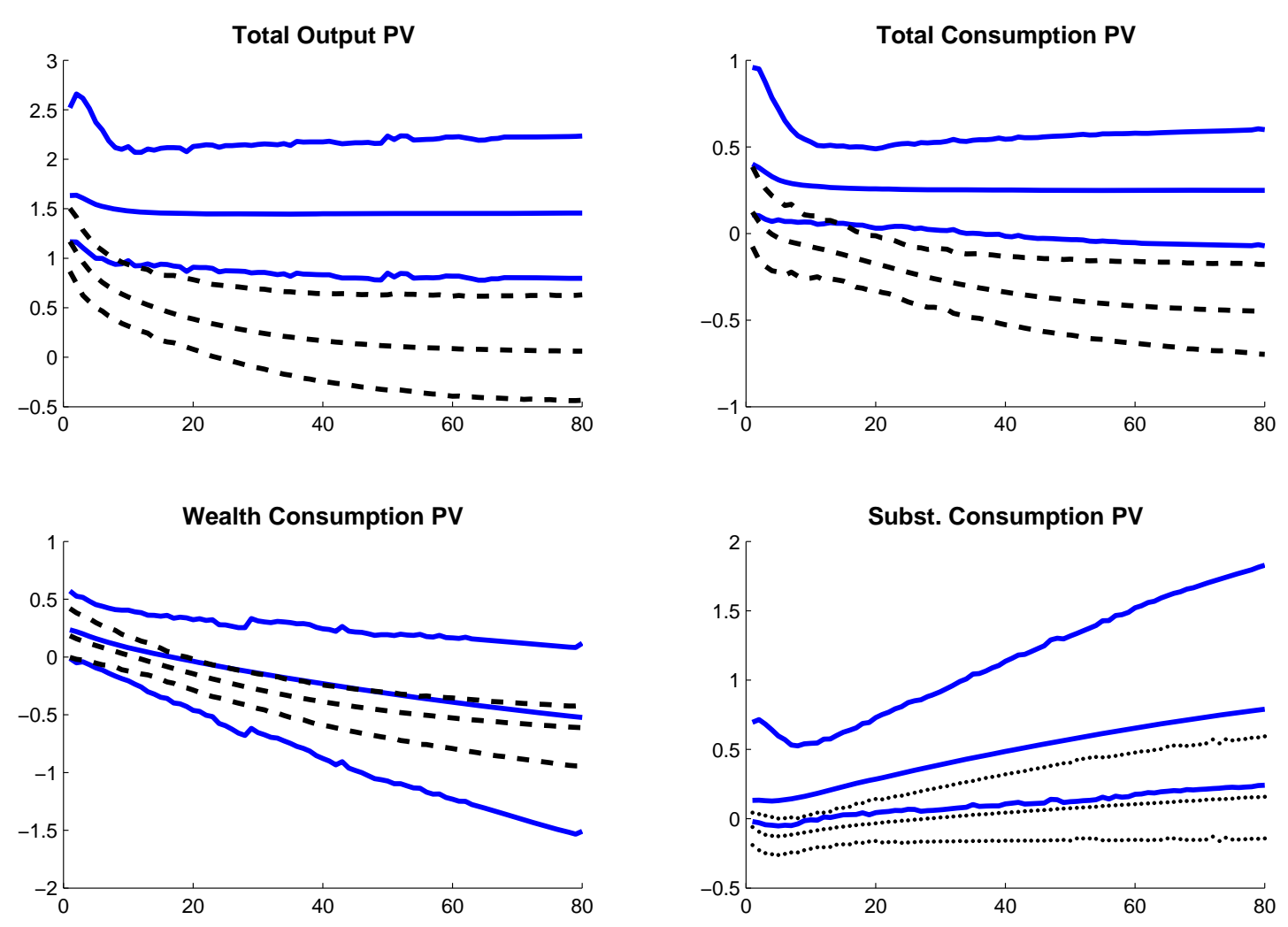

Figure 3: Present-value government spending multipliers for output and consumption at various horizons, 90-percent probability bands. Consumption multipliers are decomposed into components due to wealth and substitution effects. Solid lines: Open economy model under the passive monetary-active fiscal policy regime. Dashed lines: Open economy model under the active monetary-passive fiscal policy regime. 


\section{REFERENCES}

Adolfson, M., S. Laseen, J. Lindé, and M. Villani (2007): "Bayesian Estimation of an Open Economy DSGE Model with Incomplete Pass-Through," Journal of International Economics, $72(2), 481-511$.

Baxter, M. (1995): "International Trade and Business Cycles," in Handbook of International Economics, ed. by G. Grossman, and K. Rogoff, vol. 3, pp. 1801-1864. Elsevier Science B.V., Amsterdam.

Baxter, M., And R. King (1993): "Fiscal Policy in General Equilibrium," American Economic Review, 83(3), 315-34.

Betts, C., And M. B. Devereux (1996): "The Exchange Rate in a Model of Pricing-to-Market," European Economic Review, 40(3-5), 1007-1021.

BilbiIe, F. (2011): "Nonseparable Preferences, Frisch Labor Supply, and the Consumption Multiplier of Government Spending: One Solution to a Fiscal Policy Puzzle," Journal of Money, Credit and Banking, 43(1), 221-251.

Bilbite, F., A. Meier, and G. J. Müller (2008): "What Accounts for the Changes in U.S. Fiscal Policy Transmission?," Journal of Money, Credit and Banking, 40(7), 1439-1470.

Caldara, D. (2011): "The Analytics of SVARs: A Unified Framework to Measure Fiscal Multipliers," Manuscript, Stockholm University, January.

Calvo, G. A. (1983): "Staggered Prices in a Utility Maxmimizing Model," Journal of Monetary Economics, 12(3), 383-398.

Chari, V. V., P. J. Kehoe, and E. R. McGrattan (2002): "Can Sticky Price Models Generate Volatile and Persistent Real Exchange Rates?," Review of Economic Studies, 69(3), 533-563.

Christiano, L., M. Eichenbaum, and S. Rebelo (2011): "When Is the Government Spending Multiplier Large?," Journal of Political Economy, 119(1), 78-121.

Christiano, L. J., M. Eichenbaum, and C. L. Evans (2005): "Nominal Rigidities and the Dynamic Effects of a Shock to Monetary Policy," Journal of Political Economy, 113(1), 1-45.

Cochrane, J. H. (1998): "A Frictionless View of U.S. Inflation," in NBER Macroeconomics Annual 1998, ed. by B. S. Bernanke, and J. J. Rotemberg, vol. 14, pp. 323-384. MIT Press, Cambridge, MA.

Coenen, G., C. Erceg, C. Freedman, D. Furceri, M. Kumhof, R. Lalonde, D. Laxton, J. Lindé, A. Mourougane, D. Muir, S. Mursula, C. de Resende, J. Roberts, W. Roeger, S. Snudden, M. Trabandt, and J. In't Veld (2010): "Effects of Fiscal Stimulus in Structural Models," International Monetary Fund WP/10/73, March. 
Coenen, G., and R. Straub (2004): "Non-Ricardian Households and Fiscal Policy in an Estimated DSGE Model of the Euro Area," Manuscript, European Central Bank.

Cogan, J. F., T. Cwik, J. B. Taylor, and V. Wieland (2010): "New Keynesian Versus Old Keynesian Government Spending Multipliers," Journal of Economic Dynamics and Control, 34(3), 281-295.

Cwik, T., And V. Wieland (2011): "Keynesian Government Spending Multipliers and Spillovers in the Euro Area," Economic Policy, 26(67), 493-549.

Davig, T., and E. M. Leeper (2011): "Monetary-Fiscal Policy Interactions and Fiscal Stimulus," European Economic Review, 55(2), 211-227.

Del Negro, M., F. Schorfheide, F. Smets, and R. Wouters (2004): "On the Fit and Forecasting Performance of New Keynesian Models," Federal Reserve Bank of Atlanta Working Paper 2004-37, December.

Drautzburg, T., and H. Uhlig (2011): "Fiscal Stimulus and Distortionary Taxation," $Z E W$ Centre for European Economic Research Discussion Paper No. 11-037, May.

Eggertsson, G. B. (2009): "What Fiscal Policy is Effective at Zero Interest Rates?," Federal Reserve Bank of New York Staff Report No. 402.

Erceg, C. J., L. Guerrieri, and C. J. Gust (2006): "SiGMA: A New Open Economy Model for Policy Analysis," International Journal of Central Banking, 2(1).

Faust, J., And A. Gupta (2010): "Posterior Predictive Analysis for Evaluating DSGE Models," Working Paper, Johns Hopkins University.

Forni, L., L. Monteforte, and L. Sessa (2009): "The General Equilibrium Effects of Fiscal Policy: Estimates for the Euro Area," Journal of Public Economics, 93(3-4), 559-585.

Galí, J., J. D. López-Salido, and J. Vallés (2007): "Understanding the Effects of Government Spending on Consumption," Journal of the European Economic Association, 5(1), 227-270.

GeweKe, J. (2005): Contemporary Bayesian Econometrics and Statistics. Wiley-Interscience, Malden, MA.

- (2010): Complete and Incomplete Econometric Models. Princeton University Press, Princeton, NJ.

KIM, S. (2003): "Structural Shocks and the Fiscal Theory of the Price Level in the Sticky Price Model," Macroeconomic Dynamics, 7(5), 759-782.

King, R. G. (1991): "Value and Capital in the Equilibrium Business Cycle Program," in Value and Capital Fifty Years Later, ed. by L. W. McKenzie, and S. Zamagni. MacMillan, London. 
Lancaster, T. (2004): An Introduction to Modern Bayesian Econometrics. Blackwell publishing.

Leeper, E. M. (1991): "Equilibria Under 'Active' and 'Passive' Monetary and Fiscal Policies," Journal of Monetary Economics, 27(1), 129-147.

Leeper, E. M., M. Plante, and N. Traum (2010): "Dynamics of Fiscal Financing in the United States," Journal of Econometrics, 156(2), 304-321.

Lopez-Salido, J. D., and P. Rabanal (2006): "Government Spending and Consumption-Hours Preferences," La Caixa Working Paper Series No. 02/2006, November.

Monacelli, T., and R. Perotti (2008): "Fiscal Policy, Wealth Effects, and Markups," National Bureau of Economic Research Working Paper No. 14584, December.

Romer, C., And J. Bernstein (2009): The Job Impact of the American Recovery and Reinvestment Plan. Obama Transition Team, Washington, D.C., January 9.

Sims, C. A. (1994): "A Simple Model for Study of the Determination of the Price Level and the Interaction of Monetary and Fiscal Policy," Economic Theory, 4(3), 381-399.

Smets, F., And R. Wouters (2003): "An Estimated Dynamic Stochastic General Equilibrium Model of the Euro Area," Journal of the European Economic Association, 1(5), 1123-1175.

Traum, N., And S.-C. S. Yang (2010): "When Does Government Debt Crowd Out Investment?," Center for Applied Economics and Policy Reserch Working Paper No. 2010-006, May.

Uhlig, H. (2009): "Some Fiscal Calculus," Manuscript, University of Chicago, May.

_ (2010): "Some Fiscal Calculus," American Economic Review, 100(2), 30-34.

Woodford, M. (2003): Interest and Prices: Foundations of a Theory of Monetary Policy. Princeton University Press, Princeton, N.J.

(2011): "Simple Analytics of the Government Expenditure Multiplier," American Economic Journal: Macroeconomics, 3(1), 1-35.

Zubairy, S. (2010): “On Fiscal Multipliers: Estimates from a Medium-Scale DSGE Model," Bank of Canada Working Paper 2010-30, November. 


\section{Appendix for On-Line Publication}

This appendix gives details on the log-linear approximation of the model, additional details on the calculations of the Hicksian decompositions, and some additional results not included in the main text. In particular, the additional results include: 1) ranges of present value multipliers from the non-uniform prior analysis under various model specifications, 2) ranges of present value multipliers from the uniform prior analysis under various model specifications, 3) ranges of present value multipliers from additional model specifications under the passive monetary, active fiscal policy regime, 4) model comparison analysis, and 5) ranges of present value multipliers based on an alternative ordering of the models presented in the main text. This appendix is not self-contained and assumes the reader is familiar with the contents of the main text.

\section{A Derivation of the Log-Linearized Model}

\section{A.1 The Equilibrium System.}

A.1.1 Households We define $\Lambda_{t}^{S}$ as the Lagrange multiplier associated with the savers' budget constraint and $\lambda_{t}^{S} \equiv \Lambda_{t}^{S} / P_{t}^{C}$. In addition, we define $\lambda_{t}^{S} q_{t}$ as the Lagrange multiplier associated with the capital accumulation equation, and $w_{t} \equiv W_{t} / P_{t}^{C}$, and $r_{t}^{k} \equiv R_{t}^{k} / P_{t}^{C}$.

Savers' FOC for consumption:

$$
\lambda_{t}^{S}\left(1+\tau_{t}^{c}\right)=\left(C_{t}^{S}-\theta C_{t-1}^{S}\right)^{-\gamma}
$$

Euler equation for domestic bonds:

$$
\lambda_{t}^{S}=\beta R_{t} E_{t} \frac{\lambda_{t+1}^{S}}{\pi_{t+1}^{C}}
$$

Euler equation for foreign bonds:

$$
1=\beta R_{t}^{*}\left[1-\Gamma\left(\frac{s_{t} F_{t}}{Y_{t}}\right)\right] E_{t}\left[\frac{\lambda_{t+1}^{S} s_{t+1}}{\lambda_{t}^{S} s_{t} \pi_{t+1}^{C *}}\right]
$$

where $s_{t}$ is the real exchange rate. Savers' FOC for capacity utilization:

$$
\left(1-\tau_{t}^{k}\right) r_{t}^{k}=\psi^{\prime}\left(v_{t}\right) \frac{P_{t}^{I}}{P_{t}^{C}}
$$

Savers' FOC for capital:

$$
q_{t}=\beta E_{t} \frac{\lambda_{t+1}^{S}}{\lambda_{t}^{S}}\left[\left(1-\tau_{t+1}^{k}\right) r_{t+1}^{k} v_{t+1}-\psi\left(v_{t+1}\right) \frac{P_{t+1}^{I}}{P_{t+1}^{C}}+(1-\delta) q_{t+1}\right]
$$


where $q_{t}$ is Tobin's Q. Savers' FOC for investment:

$$
\frac{P_{t}^{I}}{P_{t}^{C}}=q_{t}\left[1-\Gamma_{i}\left(\frac{I_{t}}{I_{t-1}}\right)-\Gamma_{i}^{\prime}\left(\frac{I_{t}}{I_{t-1}}\right) \frac{I_{t}}{I_{t-1}}\right]+\beta E_{t}\left[q_{t+1} \frac{\lambda_{t+1}^{S}}{\lambda_{t}^{S}} \Gamma_{i}^{\prime}\left(\frac{I_{t+1}}{I_{t}}\right)\left(\frac{I_{t+1}}{I_{t}}\right)^{2}\right]
$$

Effective capital:

$$
K_{t}=v_{t} \bar{K}_{t-1}
$$

Law of motion for capital:

$$
\bar{K}_{t}=(1-\delta) \bar{K}_{t-1}+\left[1-\Gamma_{i}\left(\frac{I_{t}}{I_{t-1}}\right)\right] I_{t}
$$

Nonsavers' real budget constraint:

$$
\left(1+\tau_{t}^{c}\right) C_{t}^{N}=\left(1-\tau_{t}^{L}\right) w_{t} L_{t}+Z_{t}^{N}
$$

A.1.2 Wage Determination. FOC for optimal wage $\left(\tilde{w}_{t} \equiv W_{t} / P_{t}^{c}\right)$ :

$$
0=E_{t}\left\{\sum_{t=0}^{\infty}\left(\beta \omega_{w}\right)^{s} \lambda_{t+s}^{S} \bar{L}_{t+s}\left[\tilde{w}_{t} \prod_{k=1}^{s}\left\{\left(\frac{\pi_{t+k}^{C}}{\pi^{C}}\right)^{\chi^{w}}\left(\frac{\pi^{C}}{\pi_{t+k}^{C}}\right)\right\}-\frac{\left(1+\eta^{w}\right) \psi \bar{L}_{t+s}^{\xi}}{\left(1-\tau_{t+s}^{L}\right) \lambda_{t+s}^{S}}\right]\right\}
$$

where

$$
\bar{L}_{t+s}=\left(\tilde{w}_{t} \prod_{k=1}^{s}\left\{\left(\frac{\pi_{t+k}^{C}}{\pi^{C}}\right)^{\chi^{w}}\left(\frac{\pi^{C}}{\pi_{t+k}^{C}}\right)\right\}\right)^{-\frac{1+\eta^{w}}{\eta^{w}}} L_{t+s}
$$

Aggregate wage evolution:

$$
w_{t}^{\frac{1}{\eta^{w}}}=\left(1-\omega_{w}\right) \tilde{w}_{t}^{\frac{1}{\eta^{w}}}+\omega_{w}\left[\left(\frac{\pi_{t-1}^{C}}{\pi^{C}}\right)^{\chi^{w}}\left(\frac{\pi^{C}}{\pi_{t}^{C}}\right) w_{t-1}\right]^{\frac{1}{\eta^{w}}}
$$

\section{A.1.3 Intermediate Goods Firms. Production function:}

$$
Y_{t}=A_{t} K_{t}^{\alpha} L_{t}^{1-\alpha}
$$

Capital-labor ration:

$$
\frac{K_{t}}{L_{t}}=\frac{w_{t}}{r_{t}^{k}} \frac{\alpha}{1-\alpha}
$$

Real marginal cost $\left(\equiv M C_{t} / P_{t}^{C}\right)$ :

$$
m c_{t}=(1-\alpha)^{\alpha-1} \alpha^{-\alpha}\left(r_{t}^{k}\right)^{\alpha} w_{t}^{1-\alpha} A_{t}^{-1}
$$


Intermediate firm's FOC for domestic price:

$$
0=E_{t}\left\{\sum_{s=0}^{\infty}\left(\beta \omega_{p}\right)^{s} \lambda_{t+s}^{S} \bar{y}_{t+s}^{H}\left[\frac{\tilde{p}_{t}^{H}}{P_{t}^{H}} \prod_{k=1}^{s}\left[\left(\frac{\pi_{t+k-1}^{H}}{\pi^{H}}\right)^{\chi^{p}}\left(\frac{\pi^{H}}{\pi_{t+k}^{H}}\right)\right]-\left(1+\eta^{p}\right) \frac{P_{t+s}^{C} m c_{t+s}}{P_{t+s}^{H}}\right]\right\}
$$

where

$$
\bar{y}_{t+s}^{H}=\left(\frac{\tilde{p}_{t}^{H}}{P_{t}^{H}} \prod_{k=1}^{s}\left[\left(\frac{\pi_{t+k-1}^{H}}{\pi^{H}}\right)^{\chi^{p}}\left(\frac{\pi^{H}}{\pi_{t+k}^{H}}\right)\right]\right)^{-\frac{1+\eta^{p}}{\eta^{p}}} Y_{t+s}^{H}
$$

Aggregate domestic price index:

$$
1=\left\{\left(1-\omega_{p}\right)\left(\frac{\tilde{p}_{t}^{H}}{P_{t}^{H}}\right)^{\frac{1}{\eta^{p}}}+\omega_{p}\left[\left(\frac{\pi_{t-1}^{H}}{\pi^{H}}\right)^{\chi^{p}}\left(\frac{\pi^{H}}{\pi_{t}^{H}}\right)\right]^{\frac{1}{\eta^{p}}}\right\}^{\eta^{p}}
$$

Intermediate firm's FOC for foreign import price:

$$
0=E_{t}\left\{\sum_{s=0}^{\infty}\left(\beta \omega_{p, x}\right)^{s} \lambda_{t+s}^{S} \bar{m}_{t+s}\left[\frac{\tilde{p}_{t}^{H *}}{P_{t}^{H *}} \prod_{k=1}^{s}\left[\left(\frac{\pi_{t+k-1}^{H *}}{\pi^{H *}}\right)^{\chi^{p, x}}\left(\frac{\pi^{H} *}{\pi_{t+k}^{H *}}\right)\right]-\left(1+\eta^{p}\right) \frac{P_{t+s}^{C} m c_{t+s}}{P_{t+s}^{H *} S_{t+s}}\right]\right\}
$$

where

$$
\bar{m}_{t+s}=\left(\frac{\tilde{p}_{t}^{H *}}{P_{t}^{H *}} \prod_{k=1}^{s}\left[\left(\frac{\pi_{t+k-1}^{H *}}{\pi^{H *}}\right)^{\chi^{p}}\left(\frac{\pi^{H *}}{\pi_{t+k}^{H *}}\right)\right]\right)^{-\frac{1+\eta^{p}}{\eta^{p}}} M_{t+s}^{*}
$$

Aggregate foreign import price index:

$$
1=\left\{\left(1-\omega_{p, x}\right)\left(\frac{\tilde{p}_{t}^{H *}}{P_{t}^{H *}}\right)^{\frac{1}{\eta^{p}}}+\omega_{p, x}\left[\left(\frac{\pi_{t-1}^{H *}}{\pi^{H *}}\right)^{\chi^{p, x}}\left(\frac{\pi^{H *}}{\pi_{t}^{H *}}\right)\right]^{\frac{1}{\eta^{p}}}\right\}^{\eta^{p}}
$$

A.1.4 Final Goods Firms Final consumption good technology:

$$
Q_{t}^{C}=\left[\left(1-\nu_{C}\right)^{\frac{1}{\mu_{C}}}\left(C_{t}^{H}\right)^{\frac{\mu_{C}-1}{\mu_{C}}}+\nu_{C}^{1} \mu_{C}\left(C_{t}^{F}\right)^{\frac{\mu_{C}-1}{\mu_{C}}}\right]^{\frac{\mu_{C}}{\mu_{C}-1}}
$$

Demand for the domestically produced and imported intermediate goods $i$ and $i^{*}$ by the final private consumption good firm:

$$
C_{t}^{H}(i)=\left(\frac{p_{t}^{H}(i)}{P_{t}^{H}}\right)^{-\frac{1+\eta^{p}}{\eta^{p}}} C_{t}^{H}, C_{t}^{F}\left(i^{*}\right)=\left(\frac{p_{t}^{F}\left(i^{*}\right)}{P_{t}^{F}}\right)^{-\frac{1+\eta^{p}}{\eta^{p}}} C_{t}^{F}
$$


Demand for the domestically produced and imported intermediate good bundles by the final private consumption good firm:

$$
C_{t}^{H}=\left(1-\nu_{C}\right)\left(\frac{P_{t}^{H}}{P_{t}^{C}}\right)^{-\mu_{C}} Q_{t}^{C}, C_{t}^{F}=\nu_{C}\left(\frac{P_{t}^{F}}{P_{t}^{C}}\right)^{-\mu_{C}} Q_{t}^{C}
$$

where

$$
P_{t}^{C}=\left[\left(1-\nu_{C}\right)\left(P_{t}^{H}\right)^{1-\mu_{C}}+\nu_{C}\left(P_{t}^{F}\right)^{1-\mu_{C}}\right]^{\frac{1}{1-\mu_{C}}}
$$

Final investment technology:

$$
Q_{t}^{I}=\left[\left(1-\nu_{I}\right)^{\frac{1}{\mu_{I}}}\left(I_{t}^{H}\right)^{\frac{\mu_{I}-1}{\mu_{I}}}+\nu_{I}^{1} \mu_{I}\left(I_{t}^{F}\right)^{\frac{\mu_{I}-1}{\mu_{I}}}\right]^{\frac{\mu_{I}}{\mu_{I}-1}}
$$

Demand for the domestically produced and imported intermediate goods $i$ and $i^{*}$ by the private investment good firm:

$$
I_{t}^{H}(i)=\left(\frac{p_{t}^{H}(i)}{P_{t}^{H}}\right)^{-\frac{1+\eta^{p}}{\eta^{p}}} I_{t}^{H}, \quad I_{t}^{F}\left(i^{*}\right)=\left(\frac{p_{t}^{F}\left(i^{*}\right)}{P_{t}^{F}}\right)^{-\frac{1+\eta^{p}}{\eta^{p}}} I_{t}^{F}
$$

Demand for the domestically produced and imported intermediate good bundles by the final private investment good firm:

$$
I_{t}^{H}=\left(1-\nu_{I}\right)\left(\frac{P_{t}^{H}}{P_{t}^{I}}\right)^{-\mu_{I}} Q_{t}^{I}, \quad I_{t}^{F}=\nu_{I}\left(\frac{P_{t}^{F}}{P_{t}^{I}}\right)^{-\mu_{I}} Q_{t}^{I}
$$

where

$$
P_{t}^{I}=\left[\left(1-\nu_{I}\right)\left(P_{t}^{H}\right)^{1-\mu_{I}}+\nu_{I}\left(P_{t}^{F}\right)^{1-\mu_{I}}\right]^{\frac{1}{1-\mu_{I}}}
$$

Final government spending technology:

$$
Q_{t}^{G}=\left[\left(1-\nu_{G}\right)^{\frac{1}{\mu_{G}}}\left(G_{t}^{H}\right)^{\frac{\mu_{G}-1}{\mu_{G}}}+\nu_{G}^{\frac{1}{\mu_{G}}}\left(G_{t}^{F}\right)^{\frac{\mu_{G}-1}{\mu_{G}}}\right]^{\frac{\mu_{G}}{\mu_{G}-1}}
$$

Demand for the domestically produced and imported intermediate goods $i$ and $i^{*}$ by the final public consumption good firm:

$$
G_{t}^{H}(i)=\left(\frac{p_{t}^{H}(i)}{P_{t}^{H}}\right)^{-\frac{1+\eta^{p}}{\eta^{p}}} G_{t}^{H}, G_{t}^{F}\left(i^{*}\right)=\left(\frac{p_{t}^{F}\left(i^{*}\right)}{P_{t}^{F}}\right)^{-\frac{1+\eta^{p}}{\eta^{p}}} G_{t}^{F}
$$

Demand for the domestically produced and imported intermediate good bundles by the final public consumption good firm:

$$
G_{t}^{H}=\left(1-\nu_{G}\right)\left(\frac{P_{t}^{H}}{P_{t}^{G}}\right)^{-\mu_{G}} Q_{t}^{G}, G_{t}^{F}=\nu_{G}\left(\frac{P_{t}^{F}}{P_{t}^{G}}\right)^{-\mu_{G}} Q_{t}^{G}
$$


where

$$
P_{t}^{G}=\left[\left(1-\nu_{G}\right)\left(P_{t}^{H}\right)^{1-\mu_{G}}+\nu_{G}\left(P_{t}^{F}\right)^{1-\mu_{G}}\right]^{\frac{1}{1-\mu_{G}}}
$$

Note that aggregating across the three final-goods firms gives the aggregate demand for the domestically produced and imported intermediate goods $i$ and $i^{*}$ :

$$
\begin{aligned}
Y_{t}^{H}(i) & \equiv C_{t}^{H}(i)+I_{t}^{H}(i)+G_{t}^{H}(i)=\left(\frac{p_{t}^{H}(i)}{P_{t}^{H}}\right)^{-\frac{1+\eta^{p}}{\eta^{p}}} Y_{t}^{H} \\
Y_{t}^{F}\left(i^{*}\right) & \equiv C_{t}^{F}\left(i^{*}\right)+I_{t}^{F}\left(i^{*}\right)+G_{t}^{F}\left(i^{*}\right)=\left(\frac{p_{t}^{F}\left(i^{*}\right)}{P_{t}^{F}}\right)^{-\frac{1+\eta^{p}}{\eta^{p}}} Y_{t}^{F}
\end{aligned}
$$

where $Y_{t}^{H} \equiv C_{t}^{H}+I_{t}^{H}+G_{t}^{H}$ and $Y_{t}^{F} \equiv C_{t}^{F}+I_{t}^{F}+G_{t}^{F}$.

A.1.5 Policy. Government budget constraint (where $b_{t} \equiv B_{t} / P_{t}^{C}$ ):

$$
b_{t}+\tau_{t}^{K} r_{t}^{k} v_{t} K_{t-1}+\tau_{t}^{L} w_{t} L_{t}+\tau_{t}^{C} C_{t}=\frac{R_{t-1} b_{t-1}}{\pi_{t}^{C}}+\frac{P_{t}^{G}}{P_{t}^{C}} G_{t}^{C}+Z_{t}^{S}+Z_{t}^{N}
$$

A.1.6 Aggregation. Aggregation of household consumption:

$$
C_{t}=\mu C_{t}^{S}+(1-\mu) C_{t}^{N}
$$

Market clearing in final consumption good market:

$$
Q_{t}^{C}=C_{t}
$$

Market clearing in final investment good market:

$$
Q_{t}^{I}=I_{t}+\psi\left(v_{t}\right) \bar{K}_{t-1}
$$

Market clearing in final government spending good market:

$$
Q_{t}^{G}=G_{t}
$$

Home aggregate resource constraint:

$$
Y_{t}=C_{t}^{H}+I_{t}^{H}+G_{t}^{H}+M_{t}^{*}
$$

where foreign imports are defined as

$$
M_{t}^{*}=C_{t}^{H *}+I_{t}^{H *}+G_{t}^{H *}
$$


Net foreign asset evolution:

$$
S_{t} B_{t}^{*}=R_{t}^{*}\left[1-\Gamma\left(\frac{s_{t} B_{t}^{*}}{Y_{t}}\right)\right] B_{t-1}^{*}+S_{t} P_{t}^{H *} M_{t}^{*}+P_{t}^{F} M_{t}
$$

A.2 Steady State. By assumption, in steady state $v=1, \psi(1)=0, \Gamma_{i}(1)=\Gamma_{i}^{\prime}(1)=0$. In addition, we assume that $\pi^{C}=1$, implying $R=1 / \beta$ and $s=1$. We normalize the relative home and foreign import price and set $p^{F}=p^{H *}=1$. This implies that all other relative prices are equal to one as well.

$$
\begin{gathered}
r^{k}=\frac{1-\beta(1-\delta)}{\beta\left(1-\tau^{K}\right)} \\
\psi^{\prime}(1)=r^{k}\left(1-\tau^{K}\right) \\
m c=\frac{1}{1+\eta^{p}} \\
w=\left[\frac{1}{1+\eta^{p}} \alpha^{\alpha}(1-\alpha)^{1-\alpha}\left(r^{k}\right)^{-\alpha}\right]^{\frac{1}{1-\alpha}} \\
\frac{K}{Y}=\left(\frac{w}{r^{k}} \frac{\alpha}{1-\alpha}\right)^{1-\alpha} \\
\frac{L}{Y}=\left(\frac{w}{r^{k}} \frac{\alpha}{1-\alpha}\right)^{-\alpha} \\
\frac{I}{Y}=\delta \frac{K}{Y} \\
\frac{C}{Y}=1-s^{G}-\delta \frac{K}{Y}
\end{gathered}
$$

where $s^{G}=\frac{G}{Y}$.

$$
\frac{Z}{Y}=(1-R) s^{B}-s^{G}+\tau^{K} r^{k} \frac{K}{Y}+\tau^{L} w \frac{L}{Y}+\tau^{C} \frac{C}{Y}
$$

where $s^{B}=\frac{b}{Y}$ and $Z^{N}=Z^{S}=Z$ by assumption.

$$
\begin{gathered}
\frac{C^{N}}{Y}=\frac{\left(1-\tau^{L}\right) w \frac{L}{Y}-\frac{Z}{Y}}{1+\tau^{C}} \\
\frac{C^{S}}{Y}=\frac{\frac{C}{Y}-\mu \frac{C^{N}}{Y}}{1-\mu} \\
\frac{C^{H}}{Y}=\frac{C^{F *}}{Y}=\left(1-\nu_{C}\right) \frac{C}{Y} \\
\frac{C^{F}}{Y}=\frac{C^{H *}}{Y}=\nu_{C} \frac{C}{Y} \\
\frac{I^{H}}{Y}=\frac{I^{F *}}{Y}=\left(1-\nu_{I}\right) \frac{I}{Y}
\end{gathered}
$$




$$
\begin{gathered}
\frac{I^{F}}{Y}=\frac{I^{H *}}{Y}=\nu_{I} \frac{I}{Y} \\
\frac{G^{H}}{Y}=\frac{G^{F *}}{Y}=\left(1-\nu_{G}\right) \frac{G}{Y} \\
\frac{G^{F}}{Y}=\frac{G^{H *}}{Y}=\nu_{G} \frac{G}{Y} \\
Y=\left[\frac{w\left(1-\tau^{L}\right)(1-\theta)^{-\gamma}}{\left(1+\tau^{C}\right)\left(1+\eta^{w}\right)}\left(\frac{L}{Y}\right)^{-\xi}\left(\frac{C^{S}}{Y}\right)^{-\gamma}\right]^{\frac{1}{\gamma+\xi}}
\end{gathered}
$$

Given $Y$, the levels of all other steady state variables can be backed out.

\section{A.3 The Log-Linearized System.}

\section{A.3.1 Households. Household FOC for consumption:}

$$
\hat{\lambda}_{t}^{S}=-\frac{\gamma}{1-\theta} \hat{C}_{t}^{S}+\frac{\gamma \theta}{1-\theta} \hat{C}_{t-1}^{S}-\frac{\tau^{C}}{1+\tau^{C}} \hat{\tau}_{t}^{C}
$$

Euler equation for domestic bonds:

$$
\hat{\lambda}_{t}^{S}=\hat{R}_{t}+E_{t} \hat{\lambda}_{t+1}^{S}-E_{t} \hat{\pi}_{t+1}^{C}
$$

Euler equation for foreign bonds:

$$
\hat{\lambda}_{t}^{S}=\hat{R}_{t}^{*}+E_{t} \hat{\lambda}_{t+1}^{S}+E_{t} \hat{s}_{t+1}-\hat{s}_{t}-E_{t} \hat{\pi}_{t+1}^{C *}-\zeta \hat{z}_{t}
$$

where $z_{t} \equiv \frac{s_{t} F_{t}}{Y_{t}}$. Combining the two bond Euler equations leads to the uncovered interest parity condition:

$$
\hat{R}_{t}-\hat{R}_{t}^{*}=E_{t} \hat{s}_{t+1}-\hat{s}_{t}+E_{t} \hat{\pi}_{t+1}^{C}-E_{t} \hat{\pi}_{t+1}^{C *}-\zeta \hat{z}_{t}
$$

Household FOC for capacity utilization:

$$
\hat{r}_{t}^{k}-\frac{\tau^{K}}{1-\tau^{K}} \hat{\tau}_{t}^{K}=\frac{\psi}{1-\psi} \hat{v}_{t}+\hat{p}_{t}^{I}
$$

where $\hat{p}_{t}^{I} \equiv \hat{P}_{t}^{I}-\hat{P}_{t}^{C}$ is the relative price, with respect to the home consumption basket, of home investment. Household FOC for capital:

$$
\hat{q}_{t}=E_{t} \hat{\lambda}_{t+1}^{S}-\hat{\lambda}_{t}^{S}+\beta\left(1-\tau^{K}\right) r^{k} E_{t} \hat{r}_{t+1}^{k}-\beta \tau^{K} r^{k} E_{t} \hat{\tau}_{t+1}^{K}+\beta(1-\delta) E_{t} \hat{q}_{t+1}
$$

Household FOC for investment:

$$
\frac{1}{s} \hat{p}_{t}^{I}+(1+\beta) \hat{I}_{t}-\frac{1}{s} \hat{q}_{t}-\beta E_{t} \hat{I}_{t+1}=\hat{I}_{t-1}
$$


Effective capital:

$$
\hat{K}_{t}=\hat{v}_{t}+\hat{\bar{K}}_{t-1}
$$

Law of motion for capital:

$$
\hat{\bar{K}}_{t}=(1-\delta) \hat{\bar{K}}_{t-1}+\delta \hat{I}_{t}
$$

Nonsavers' real budget constraint:

$$
\tau^{C} C^{N} \hat{\tau}_{t}^{C}+\left(1+\tau^{C}\right) C^{N} \hat{C}_{t}^{N}=\left(1-\tau^{L}\right) w L\left[\hat{w}_{t}+\hat{L}_{t}\right]-\tau^{L} w L \hat{\tau}_{t}^{L}+Z^{N} \hat{Z}_{t}^{N}
$$

A.3.2 Wage Determination. Combining and log-linearizing equations (25)-(26) leads to

$$
\begin{aligned}
& E_{t} \sum_{s=0}^{\infty}\left[\hat{\tilde{w}}_{t}+\left(1+\frac{\xi\left(1+\eta^{w}\right)}{\eta^{w}}\right) \sum_{k=1}^{s}\left\{\chi^{w} \hat{\pi}_{t+k-1}^{C}-\hat{\pi}_{t+k}^{C}\right\}+\hat{\lambda}_{t+s}^{S}-\frac{\tau^{L}}{1-\tau^{L}} \hat{\tau}_{t+s}^{L}\right] \\
& =E_{t} \sum_{s=0}^{\infty} \xi\left\{\hat{L}_{t+s}-\frac{1+\eta^{w}}{\eta^{w}}\left[\hat{\tilde{w}}_{t}-\hat{w}_{t+s}\right]\right\}
\end{aligned}
$$

This can be rewritten as

$$
\begin{aligned}
\frac{1+\xi\left(\frac{1+\eta^{w}}{\eta^{w}}\right)}{1-\beta \omega_{w}} \hat{\tilde{w}}_{t}= & \xi \hat{L}_{t}-\hat{\lambda}_{t}^{S}+\frac{\tau^{L}}{1-\tau^{L}} \hat{\tau}_{t}^{L}+\xi\left(\frac{1+\eta^{w}}{\eta^{w}}\right) \hat{w}_{t} \\
& +\frac{\beta \omega_{w}}{1-\beta \omega_{w}}\left[1+\xi\left(\frac{1+\eta^{w}}{\eta^{w}}\right)\right] E_{t}\left(\hat{\tilde{w}}_{t+1}-\chi^{w} \hat{\pi}_{t}^{C}+\hat{\pi}_{t+1}^{C}\right)
\end{aligned}
$$

Log-linearizing equation (27) leads to

$$
\hat{w}_{t}=\left(1-\omega_{w}\right) \hat{\tilde{w}}_{t}+\omega_{w}\left(\hat{w}_{t-1}+\chi^{w} \hat{\pi}_{t-1}^{C}-\hat{\pi}_{t}^{C}\right)
$$

Combining the last two equations leads to the log-linearized wage equation

$$
\begin{aligned}
\hat{w}_{t}= & \frac{1}{1+\beta} \hat{w}_{t-1}+\frac{\beta}{1+\beta} E_{t} \hat{w}_{t+1}+\frac{\chi^{w}}{1+\beta} \hat{\pi}_{t-1}^{C}-\frac{1+\beta \chi^{w}}{1+\beta} \hat{\pi}_{t}^{C}+\frac{\beta}{1+\beta} E_{t} \hat{\pi}_{t+1}^{C} \\
& -\kappa_{w}\left[\hat{w}_{t}-\xi \hat{L}_{t}-\frac{\tau^{L}}{1-\tau^{L}} \hat{\tau}_{t}^{L}+\hat{\lambda}_{t}^{S}\right]
\end{aligned}
$$

where $\kappa_{w} \equiv\left(1-\beta \omega_{w}\right)\left(1-\omega_{w}\right) /\left[\omega_{w}(1+\beta)\left(1+\xi\left(1+\frac{1}{\eta^{w}}\right)\right)\right]$.

\section{A.3.3 Intermediate Goods Firms. Production function:}

$$
\hat{Y}_{t}=\hat{A}_{t}+\alpha \hat{K}_{t}+(1-\alpha) \hat{L}_{t}
$$

Capital-labor ratio:

$$
\hat{r}_{t}^{k}-\hat{w}_{t}=\hat{L}_{t}-\hat{K}_{t}
$$


Marginal cost:

$$
\hat{m} c_{t}=\alpha \hat{r}_{t}^{k}+(1-\alpha) \hat{w}_{t}-\hat{A}_{t}
$$

Log-linearizing equation (31) leads to

$$
0=E_{t} \sum_{s=0}^{\infty}\left(\beta \omega_{p}\right)^{s}\left\{\left(\hat{\tilde{p}}_{t}^{H}-\hat{P}_{t}^{H}\right)-\hat{m} c_{t+s}-\hat{P}_{t+s}^{C}+\hat{P}_{t+s}^{H}+\sum_{k=1}^{s}\left[\chi_{p} \hat{\pi}_{t+k-1}^{H}-\hat{\pi}_{t+k}^{H}\right]\right\}
$$

This can be written as

$$
\frac{1}{1-\beta \omega_{p}}\left(\hat{\tilde{p}}_{t}^{H}-\hat{P}_{t}^{H}\right)=\hat{m} c_{t}+\hat{P}_{t}^{C}-\hat{P}_{t}^{H}-\frac{\beta \omega_{p}}{1-\beta \omega_{p}} E_{t}\left[\left(\hat{\tilde{p}}_{t+1}^{H}-\hat{P}_{t+1}^{H}\right)-\chi_{p} \hat{\pi}_{t}^{H}+\hat{\pi}_{t+1}^{H}\right]
$$

log-linearizing equation (32) leads to

$$
0=\left(1-\omega_{p}\right)\left(\hat{\tilde{p}}_{t}^{H}-\hat{P}_{t}^{H}\right)+\omega_{p}\left(\chi_{p} \hat{\pi}_{t-1}^{H}-\hat{\pi}_{t}^{H}\right)
$$

Combining the last two equations leads to the domestic Phillips curve

$$
\hat{\pi}_{t}^{H}=\frac{\beta}{1+\chi_{p} \beta} E_{t} \hat{\pi}_{t+1}^{H}+\frac{\chi_{p}}{1+\chi_{p} \beta} \hat{\pi}_{t-1}^{H}=\kappa_{p}\left(\hat{m} c_{t}-\hat{p}_{t}^{H}\right)
$$

where $\hat{p}_{t}^{H} \equiv \hat{P}_{t}^{H}-\hat{P}_{t}^{C}$ and $\kappa_{p} \equiv\left[\left(1-\beta \omega_{p}\right)\left(1-\omega_{p}\right)\right] /\left[\omega_{p}\left(1+\beta \chi_{p}\right)\right]$. Similarly, from log-linearizing equations (33)-(34), we get the foreign import Phillips curve

$$
\hat{\pi}_{t}^{H *}=\frac{\beta}{1+\chi^{p, x} \beta} E_{t} \hat{\pi}_{t+1}^{H *}+\frac{\chi^{p, x}}{1+\chi^{p, x} \beta} \hat{\pi}_{t-1}^{H *}+\kappa_{p, x}\left(\hat{m} c_{t}-\hat{s}_{t}-\hat{p}_{t}^{H *}\right)
$$

where $\hat{p}_{t}^{H *} \equiv \hat{P}_{t}^{H *}-\hat{P}_{t}^{C *}$ and $\kappa_{p, x} \equiv\left[\left(1-\beta \omega_{p, x}\right)\left(1-\omega_{p, x}\right)\right] /\left[\omega_{p, x}\left(1+\beta \chi^{p, x}\right)\right]$.

A.3.4 Final Goods Firms. Combining equations (35) and (51) gives the final consumption good technology:

$$
\hat{C}_{t}=\left(1-\nu_{C}\right) \hat{C}_{t}^{H}+\nu_{C} \hat{C}_{t}^{F}
$$

Consumption price index, from equation (38):

$$
\left(1-\nu_{C}\right) \hat{p}_{t}^{H}+\nu_{C} \hat{p}_{t}^{F}=0
$$

Home demand for imported consumption, from equation (37):

$$
\hat{C}_{t}^{F}=\mu_{C} \hat{p}_{t}^{F}+\hat{C}_{t}
$$

Combining equations (39) and (52) gives the final investment good technology:

$$
\hat{I}_{t}+\frac{\psi^{\prime}(1)}{\delta} \hat{v}_{t}=\left(1-\nu_{I}\right) \hat{I}_{t}^{H}+\nu_{I} \hat{I}_{t}^{F}
$$


Investment price index, from equation (42):

$$
\left(1-\nu_{I}\right) \hat{p}_{t}^{H}+\nu_{I} \hat{p}_{t}^{F}=\hat{p}_{t}^{I}
$$

Home demand for imported investment, from equation (41):

$$
\hat{I}_{t}^{F}=\mu_{I} \hat{p}_{t}^{F}+\hat{I}_{t}+\frac{\psi^{\prime}(1)}{\delta} \hat{v}_{t}
$$

Combining equations (43) and (53) gives the final government spending technology:

$$
\hat{G}_{t}=\left(1-\nu_{G}\right) \hat{G}_{t}^{H}+\nu_{G} \hat{G}_{t}^{F}
$$

Government spending price index, from equation (46):

$$
\left(1-\nu_{G}\right) \hat{p}_{t}^{H}+\nu_{G} \hat{p}_{t}^{F}=\hat{p}_{t}^{G}
$$

Home demand for imported government spending, from equation (45):

$$
\hat{G}_{t}^{F}=\mu_{G} \hat{p}_{t}^{F}+\hat{G}_{t}
$$

Home inflation link to the relative price:

$$
\hat{\pi}_{t}^{H}=\hat{\pi}_{t}^{C}+\hat{p}_{t}^{H}-\hat{p}_{t-1}^{H}
$$

Foreign import inflation link to the relative price:

$$
\hat{\pi}_{t}^{H *}=\hat{\pi}_{t}^{C *}+\hat{p}_{t}^{H *}-\hat{p}_{t-1}^{H *}
$$

A.3.5 PoLICY. Government budget constraint:

$$
\begin{aligned}
& R b\left(\hat{R}_{t-1}+\hat{b}_{t-1}-\hat{\pi}_{t}^{C}\right)+G\left(\hat{G}_{t}+\hat{p}_{t}^{G}\right)+Z^{S} \hat{Z}_{t}^{S}+Z^{N} \hat{Z}_{t}^{N} \\
& =b \hat{b}_{t}+\tau^{K} r^{K} K\left(\hat{\tau}_{t}^{K}+\hat{r}_{t}^{K}+\hat{K}_{t}\right)+\tau^{L} w L\left(\hat{\tau}_{t}^{L}+\hat{w}_{t}+\hat{L}_{t}\right)+\tau^{C} C\left(\hat{\tau}_{t}^{C}+\hat{C}_{t}\right)
\end{aligned}
$$

where $\hat{p}_{t}^{G} \equiv \hat{P}_{t}^{G}-\hat{P}_{t}^{C}$.

A.3.6 Aggregation. Aggregation of household consumption:

$$
C \hat{C}_{t}=C^{S}(1-\mu) \hat{C}_{t}^{S}+C^{N} \mu \hat{C}_{t}^{N}
$$

Home aggregate resource constraint:

$$
Y \hat{Y}_{t}=C^{H} \hat{C}_{t}^{H}+I^{H} \hat{I}_{t}^{H}+G^{H} \hat{G}_{t}^{H}+M^{*} \hat{M}_{t}^{*}
$$


Home imports:

$$
M \hat{M}_{t}=C^{F} \hat{C}_{t}^{F}+I^{F} \hat{I}_{t}^{F}+G^{F} \hat{G}_{t}^{F}
$$

Net foreign asset evolution:

$$
Y \hat{z}_{t}=R^{*} Y \hat{z}_{t-1}+M^{*}\left(\hat{s}_{t}+\hat{p}_{t}^{H *}+\hat{M}_{t}^{*}\right)-M\left(\hat{p}_{t}^{F}+\hat{M}_{t}\right)
$$

\section{B Hicksian Decompositions Details}

B.1 Sticky Wages To calculate the dynamic Hicksian wealth and substitution effects, we first calculate the discounted lifetime utility associated with the initial steady-state allocations (barred variables):

$$
\bar{U}=\frac{1}{1-\beta}\left[\frac{(\bar{C}-\theta \bar{C})^{1-\gamma}}{1-\gamma}-\frac{\bar{L}^{1+\xi}}{1+\xi}\right]
$$

Let the paths of consumption and labor following a one-percent government spending increase be denoted by $\left\{\hat{C}_{t}, \hat{L}_{t}\right\}_{t=0}^{\infty}$ and define $U^{\text {total }}$ as the present discounted utility associated with this path, approximated as

$$
U^{\text {total }}=\frac{1}{\bar{U}} \sum_{t=0}^{\infty} \beta^{t}\left[\bar{C}^{1-\gamma}(1-\theta)^{-\gamma} \hat{C}_{t}-\theta \bar{C}^{1-\gamma}(1-\theta)^{-\gamma} \hat{C}_{t-1}-\bar{L}^{1+\xi} \hat{L}_{t}\right]
$$

The wealth effect is computed as the constant values of consumption and nominal wages such that, at the initial steady-state prices and steady-state labor, present discounted utility equals $U^{\text {total }} .^{12}$ That is, the constant values of consumption and nominal wages $\left\{\hat{C}^{\text {wealth }}, \hat{\tilde{W}}^{\text {wealth }}\right\}$ that satisfy

$$
\begin{aligned}
U^{\text {total }} & =\frac{1}{(1-\beta) \bar{U}}\left[\bar{C}^{1-\gamma}(1-\theta)^{1-\gamma} \hat{C}^{\text {wealth }}\right] \\
0 & =\hat{\tilde{W}}^{\text {wealth }}-\gamma \hat{C}^{\text {wealth }}
\end{aligned}
$$

The consumption substitution effect is then

$$
\hat{C}_{t}^{s u b}=\hat{C}_{t}-\hat{C}^{\text {wealth }}
$$

Wealth and substitution consumption multipliers are calculated as

$$
\begin{gathered}
\text { Wealth Present Value Multiplier }(k)=\frac{E_{t} \sum_{t=0}^{k}\left(\prod_{i=0}^{j} \bar{R}^{-1}\right) \Delta C^{\text {wealth }}}{E_{t} \sum_{t=0}^{k}\left(\prod_{i=0}^{j} R_{t+i}^{-1}\right) \Delta G_{t+j}} \\
\text { Substitution Present Value Multiplier }(k)=\frac{E_{t} \sum_{t=0}^{k}\left(\prod_{i=0}^{j} R_{t+i}^{-1}\right) \Delta C_{t+j}^{s u b}}{E_{t} \sum_{t=0}^{k}\left(\prod_{i=0}^{j} R_{t+i}^{-1}\right) \Delta G_{t+j}}
\end{gathered}
$$

\footnotetext{
${ }^{12}$ We compute it as constant values of consumption and wages because, in the sticky wage setup, the choice variable for the household is the nominal wage rate.
} 
B.2 Two Housenold Models To calculate the dynamic Hicksian wealth and substitution effects when both savers and non-savers are present in the model, we first calculate the wealth and substitution effects for savers as outlined above. Since non-savers do not have a wage rate or laborleisure decision, ${ }^{13}$ their consumption simply moves one-for-one with changes in their disposable income. As such, any change in consumption is due entirely to per-period income (wealth) effects, so that $\hat{C}_{t}^{N}=\left(C_{t}^{N}\right)^{\text {wealth }}$ and $\left(C_{t}^{N}\right)^{\text {sub }}=0$.

Total consumption wealth and substitution effects then are calculated as

$$
\begin{aligned}
C_{t}^{\text {wealth }} & =(1-\mu) \frac{\bar{C}^{S}}{\bar{C}}\left(C_{t}^{S}\right)^{\text {wealth }}+\mu \frac{\bar{C}^{N}}{\bar{C}}\left(C_{t}^{N}\right)^{\text {wealth }} \\
C_{t}^{\text {sub }} & =(1-\mu) \frac{\bar{C}^{S}}{\bar{C}}\left(C_{t}^{S}\right)^{\text {sub }}+\mu \frac{\bar{C}^{N}}{\bar{C}}\left(C_{t}^{N}\right)^{\text {sub }}
\end{aligned}
$$

Wealth and substitution consumption multipliers are calculated as before:

$$
\begin{gathered}
\text { Wealth Present Value Multiplier }(k)=\frac{E_{t} \sum_{t=0}^{k}\left(\prod_{i=0}^{j} \bar{R}^{-1}\right) \Delta C^{\text {wealth }}}{E_{t} \sum_{t=0}^{k}\left(\prod_{i=0}^{j} R_{t+i}^{-1}\right) \Delta G_{t+j}} \\
\text { Substitution Present Value } \operatorname{Multiplier}(k)=\frac{E_{t} \sum_{t=0}^{k}\left(\prod_{i=0}^{j} R_{t+i}^{-1}\right) \Delta C_{t+j}^{s u b}}{E_{t} \sum_{t=0}^{k}\left(\prod_{i=0}^{j} R_{t+i}^{-1}\right) \Delta G_{t+j}}
\end{gathered}
$$

\section{Additional Results}

C.1 Various Model Multipliers Tables 9, 10, and 11 list the median and 95\% intervals for present value output, consumption, and investment multipliers, respectively, generated using the non-uniform priors (Refer to table 2 in the main text for the prior distributions). Several additional model specifications are considered in addition to the five models in the main text. Details of each model specification are listed below.

- RBC Lump-Sum Finance: basic real business cycle model with flexible prices, as in Baxter and King (1993).

- RBC Labor Tax Finance: basic real business cycle model with flexible prices and distortionary labor taxes adjusting to finance debt, similar to ?.

- RBC Distortionary Finance: Model 1 in the main text. Basic real business cycle model with flexible prices and government spending, lump-sum transfers, distortionary labor and capital taxes all adjusting to finance debt, similar to Leeper, Plante, and Traum (2010).

- RBC $\frac{B}{Y}$ Varies: Same specification as RBC Distortionary Finance, additionally allowing a prior on the value for the steady state debt to gdp ratio.

\footnotetext{
${ }^{13}$ We assume non-savers simply set their wage to be the average wage of the savers. Since non-savers face the same labor demand schedule as savers, they work the same number of hours as the average for savers.
} 
- RBC Fiscal Steady State Varies: Same specification as RBC Distortionary Finance, additionally allowing priors on all steady state fiscal values.

- RBC Real Frictions: Model 2 in the main text. Introduces real frictions (habit formation, investment adjustment costs, and capacity utilization) to the RBC Distortionary Finance model.

- NK Sticky Price: basic New Keynesian model with sticky prices and flexible wages.

- NK Sticky Price \& Wage: Model 3 in the main text. New Keynesian model with sticky prices and sticky wages.

- NK Nonsavers: Model 4 in the main text. Introduces non-savers to the NK Sticky Price \& Wage model.

- Open NK Fin. Autarky: G NonTraded: Model 5 in the main text. Introduces open economy features by considering a two-country world economy and allowing consumption and investment to consist of domestic and imported goods. Under financial autarky, there is no trade in assets, and the home and foreign countries experiences balanced trade each period.

- Open NK Fin. Autarky: G Traded: Allows government spending to consist of both domestic and imported goods in the financial autarky version of the open economy model.

- Open NK Fin. Integration: G NonTraded: Introduces open economy features by considering a two-country world economy and allowing consumption and investment to consist of domestic and imported goods. With financial integration, we allow the home country to borrow/lend internationally with a risk-free bond, and subject the home country to a risk premium that depends on the net foreign asset position.

- Open NK Fin. Integration: G Traded: Allows government spending to consist of both domestic and imported goods in the financial integration version of the open economy model.

Looking across model specifications, several trends emerge. Over time, distortionary financing creates costly disincentive effects as labor and capital taxes increase, causing output multipliers to double in the long run, compared to a model with only lump-sum tax adjustments (comparing rows 1-3 in tables 9, 10, and 11). Allowing multiple distortionary instruments to adjust to debt substantially increases the long run negative output multipliers. Most research on fiscal multipliers only allows one fiscal instrument to adjust to debt at a time, ${ }^{14}$ suggesting these works might be biased towards higher long run multipliers if multiple types of expenditures and taxes adjust to debt in practice.

\footnotetext{
${ }^{14}$ Indeed, following Uhlig (2010) and Coenen, Erceg, Freedman, Furceri, Kumhof, Lalonde, Laxton, Lindé, Mourougane, Muir, Mursula, de Resende, Roberts, Roeger, Snudden, Trabandt, and in't Veld (2010), a common practice in the literature is to allow labor taxes to adjust to debt.
} 
Short-run fiscal multipliers are largely insensitive to variations in steady-state fiscal parameters (rows 4 and 5 in tables 9, 10, and 11). However, long-run multipliers are more sensitive to the steady-state fiscal values, suggesting long-run present value multipliers produced from the model in IMF10/73 may vary from differences in steady state calibrations across models.

Looking across the various open economy specifications (the last four rows in tables 9, 10, and 11), it appears the open economy model in the main text (Model 5) delivers the largest output multipliers. Multipliers are smaller with international financial integration. Under financial autarky, trade in goods must be balanced each period. This decreases the import substitution effect, as nominal imports are constrained to equal exports. With financial integration, the domestic economy initially runs trade deficits and consumes more imports, causing output to decrease more in the short run. Multipliers also are smaller when government spending is a traded good, as part of the increase in government spending goes directly to the foreign country.

Tables 12, 13, and 14 list the median and 95\% intervals for present value output, consumption, and investment multipliers, respectively, generated using the uniform priors (Refer to table 6 in the main text for the prior distributions). Looking across model specifications, we see that model restrictions impose the same restrictions on multipliers generated with non-uniform or uniform priors. The uniform priors increase the probability of parameter draws from a larger region of the parameter space. This, in turn, allows a larger range of multipliers (relative to the counterparts in tables 9, 10, and 11). The prior specification appears to be most informative about multipliers over longer horizons.

Tables 15, 16, and 17 list the median and 95\% intervals for present value output, consumption, and investment multipliers, respectively, generated under the passive monetary, active fiscal policy regime. In the baseline New Keynesian model without sticky wages (the first row of tables 15, 16, and 17), there is a positive probability of short-run output multipliers being less than one and short-run consumption and investment multipliers being negative. However, across all model specifications, there is a substantial probability of large output multipliers, coupled with positive consumption and investment multipliers.

C.2 Model Comparisons We assume that the multipliers from data follow uniform distributions and use the distributions in Caldara (2011). Caldara (2011) shows the impact multiplier varies dramatically with the output elasticity of spending. We restrict the range for the elasticity to be between -0.7 and 0.7, implying the following distributions for impact multipliers: $\frac{\Delta Y}{\Delta G} \sim U[-0.7,1.49]$, $\frac{\Delta C}{\Delta G} \sim U[-0.48,0.26]$, and $\frac{\Delta I}{\Delta G} \sim U[-0.21,0.1]$. We calculate the mean impact multiplier implied from these distributions and compare how likely our model specifications can reproduce these values (that is, we calculate $p\left(\omega \mid A_{j}\right)$ for each model $A_{j}$ ). Tables 18 and 19 give the model comparisons for the baseline and uniform priors, respectively. Various model specifications are better at matching different multipliers. For instance, although models 1 and 2 match the mean output impact multiplier better than model 5 , they are worse at producing the mean investment impact multiplier. 
C.3 Alternative Model Ordering Table 20 lists the median and 95\% intervals for present value output multipliers generated using an alternative ordering of the five models presented in the main text. As noted in Galí, López-Salido, and Vallés (2007), non-savers are vital for multipliers when coupled with nominal wage rigidities. To explore the effects of non-savers, we consider an alternative ordering of models. Model 1 is a standard RBC closed-economy model. Model 2 adds non-savers to the standard RBC closed-economy framework ${ }^{15}$. Model 3 additionally allows for real frictions (investment adjustment costs, habit formation, and capacity utilization). Model 4 is a standard NK model with sticky prices and wages, which introduces a role for monetary-fiscal policy interactions. And model 5 allows for an open-economy structure. Note that models 1 and 5 are the same as the models presented in the main text. Table 20 reveals that non-savers have no substantial impact on multipliers when the labor market is perfectly competitive.

\footnotetext{
${ }^{15}$ Since there are no sticky wages in this framework, both non-savers and savers make a intra-temporal labor-leisure decision given the market wage rate
} 


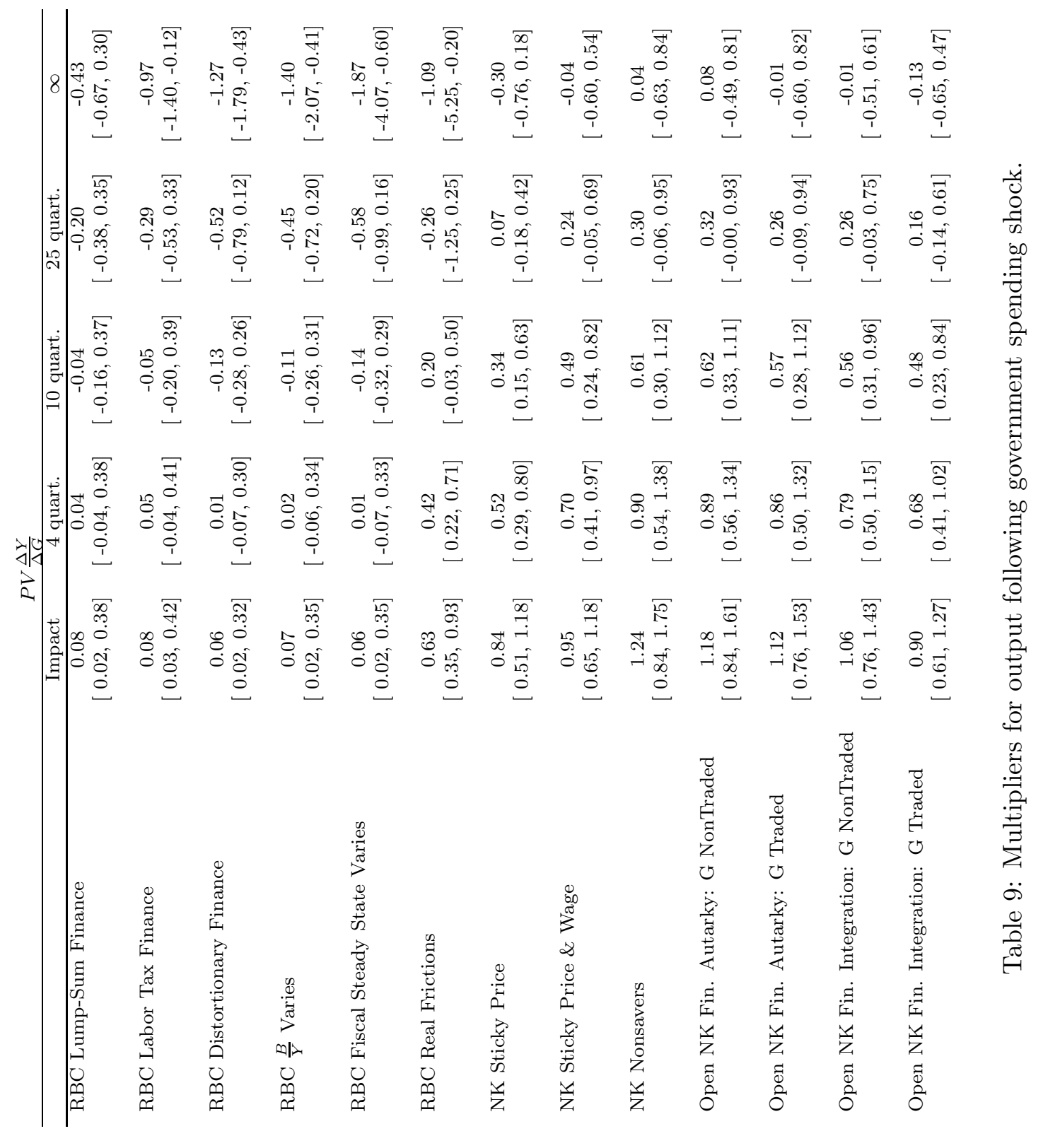




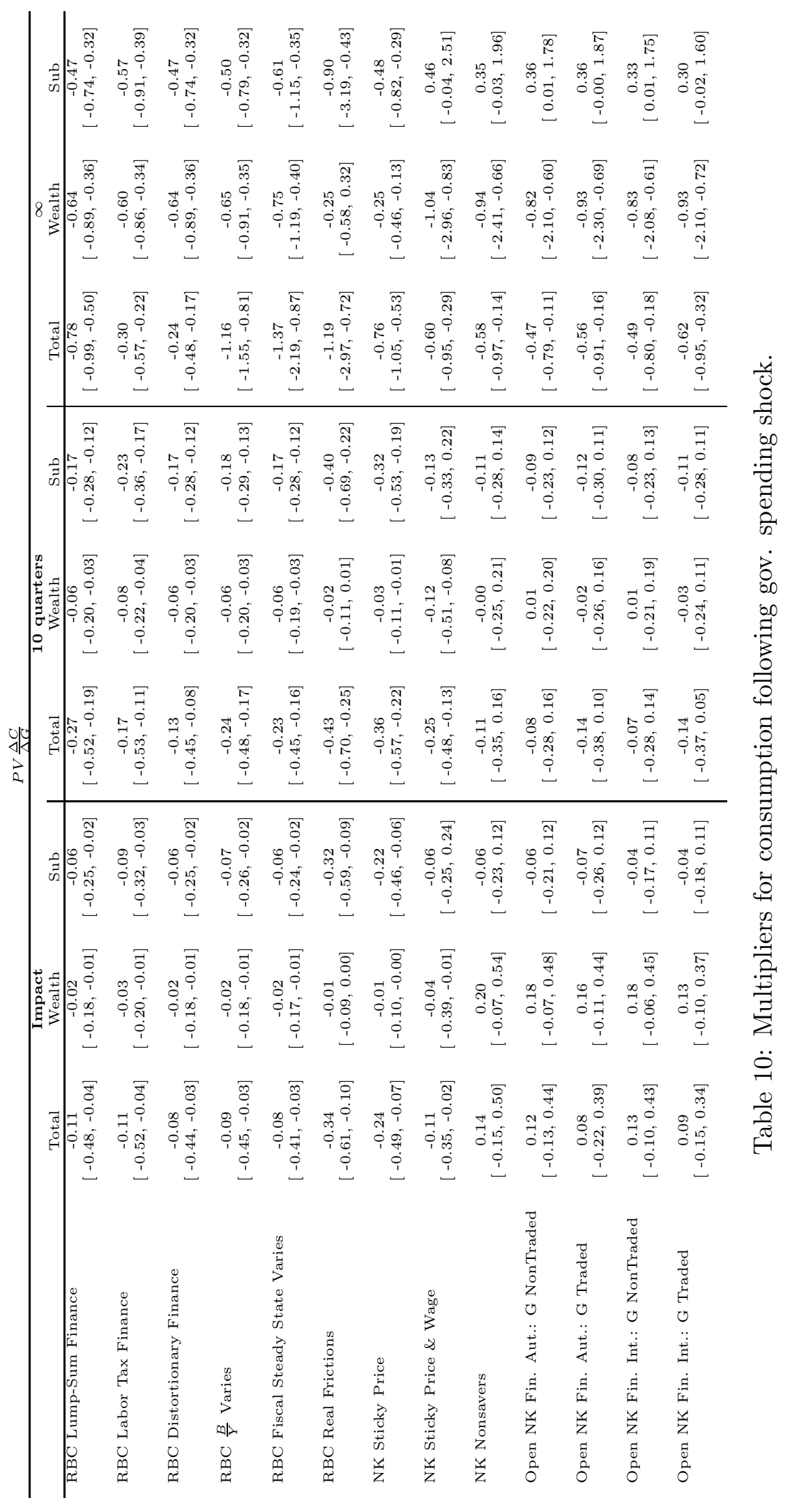




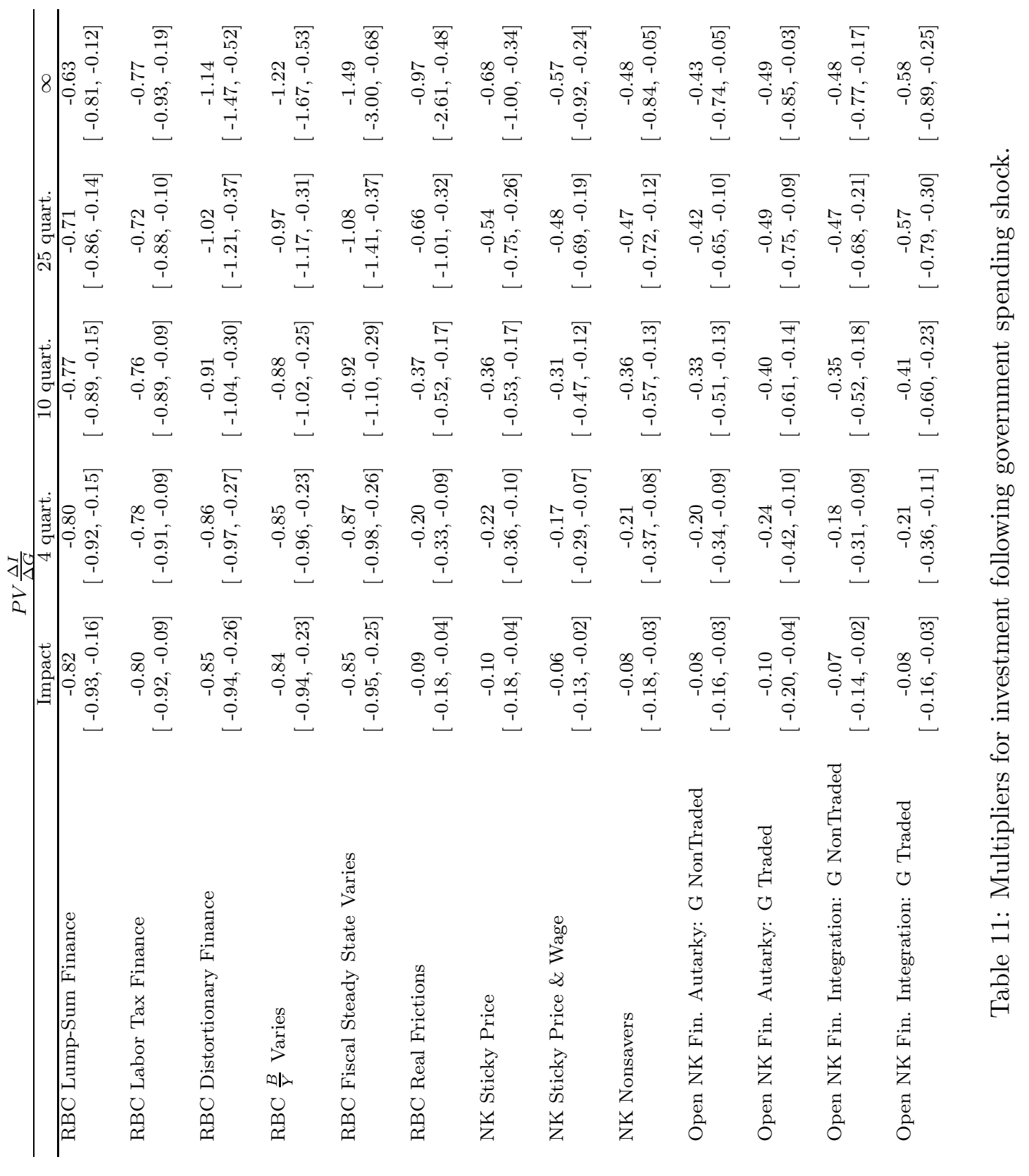




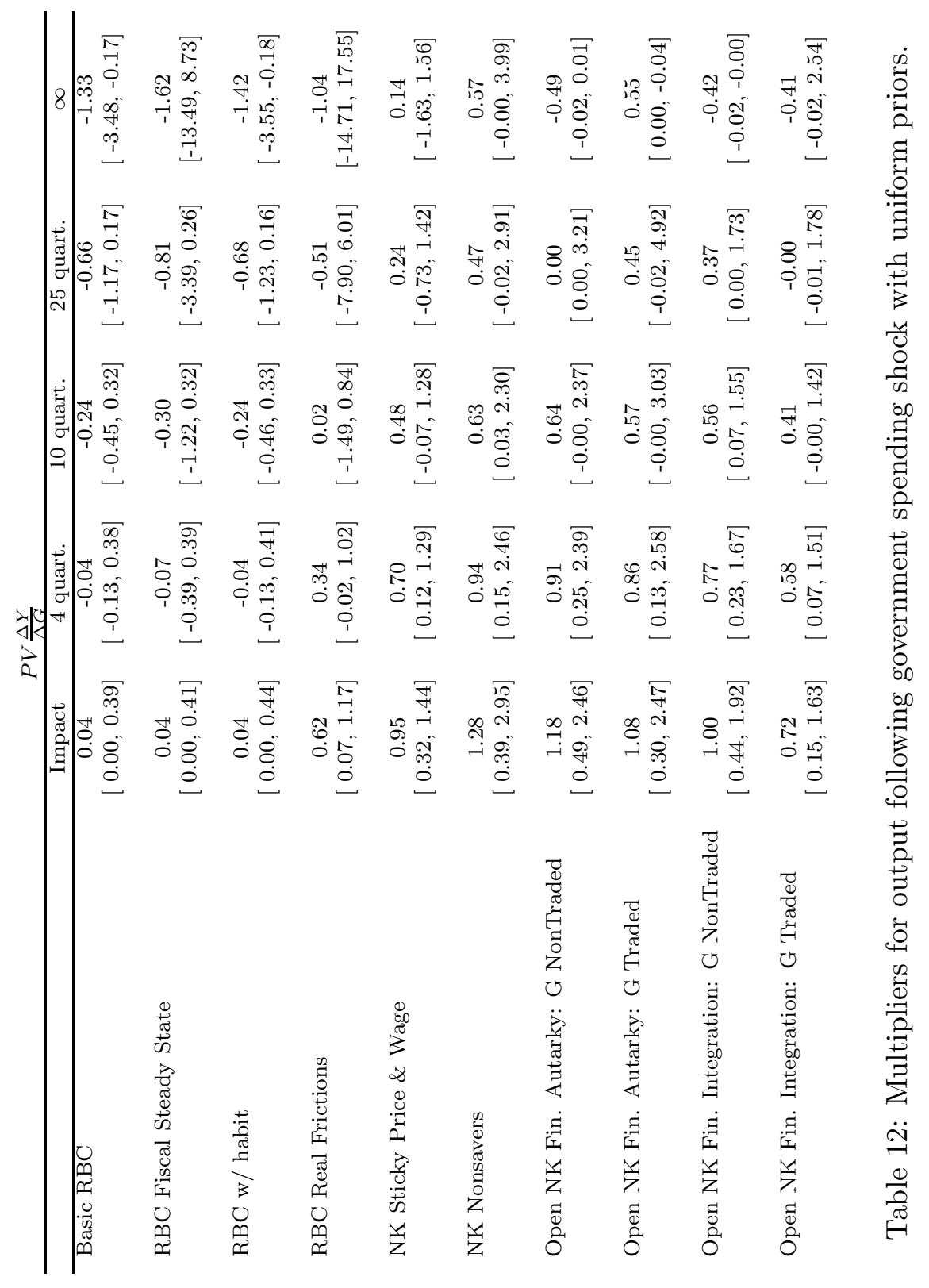




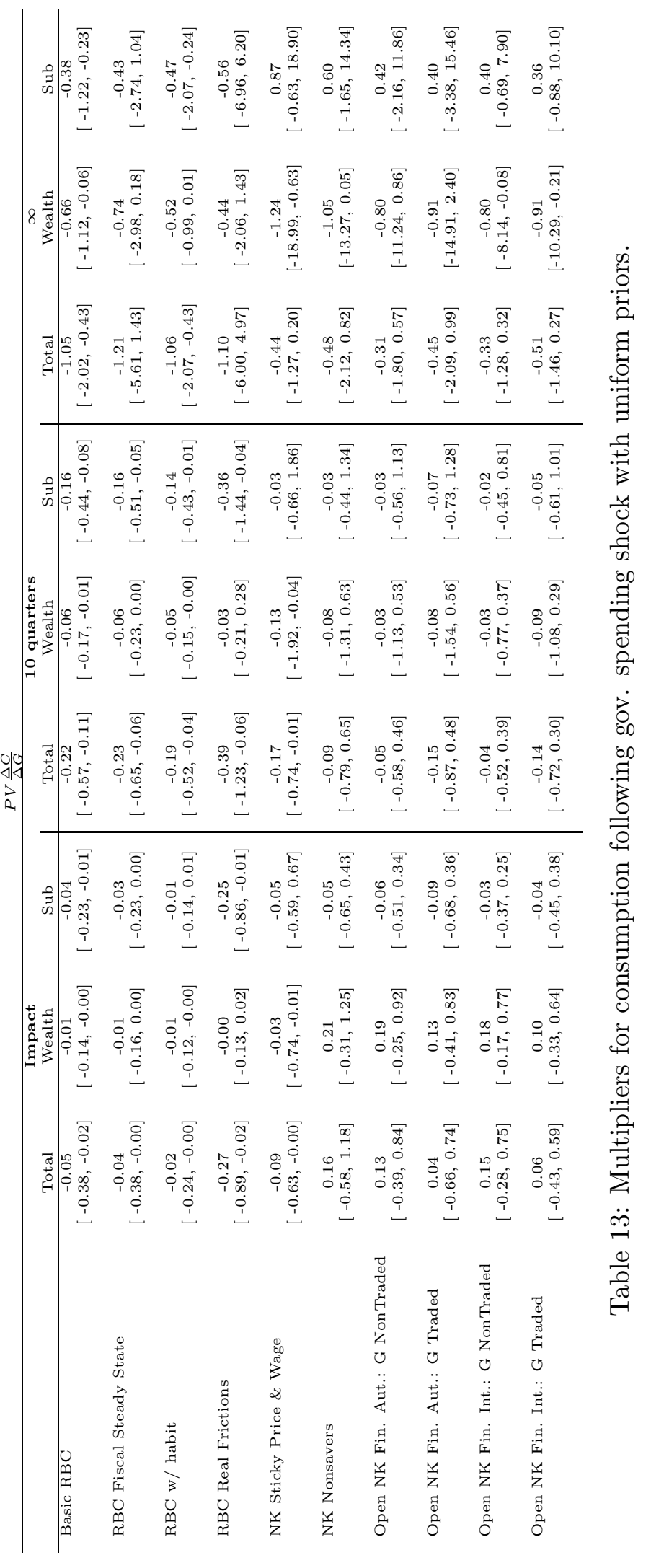




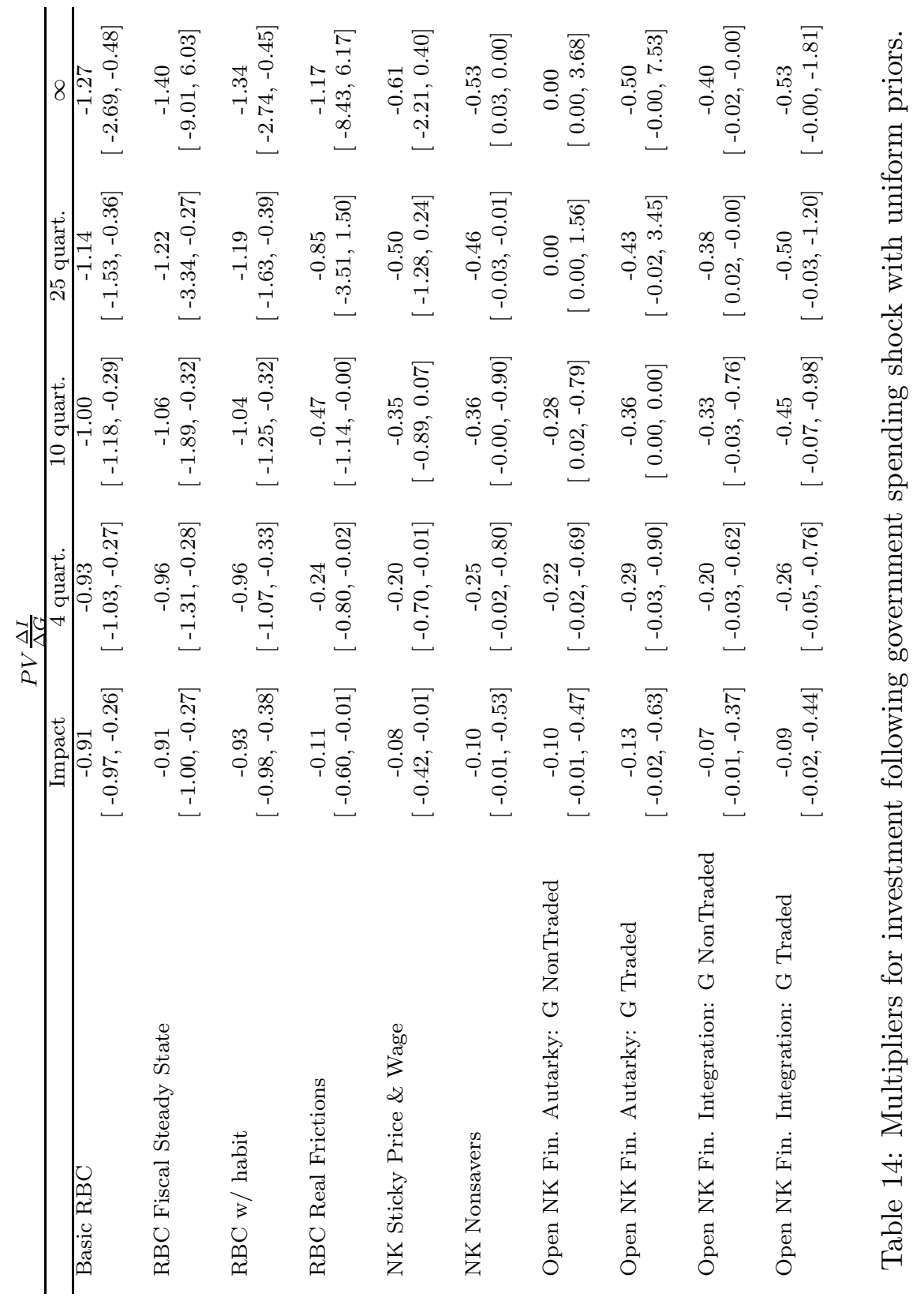




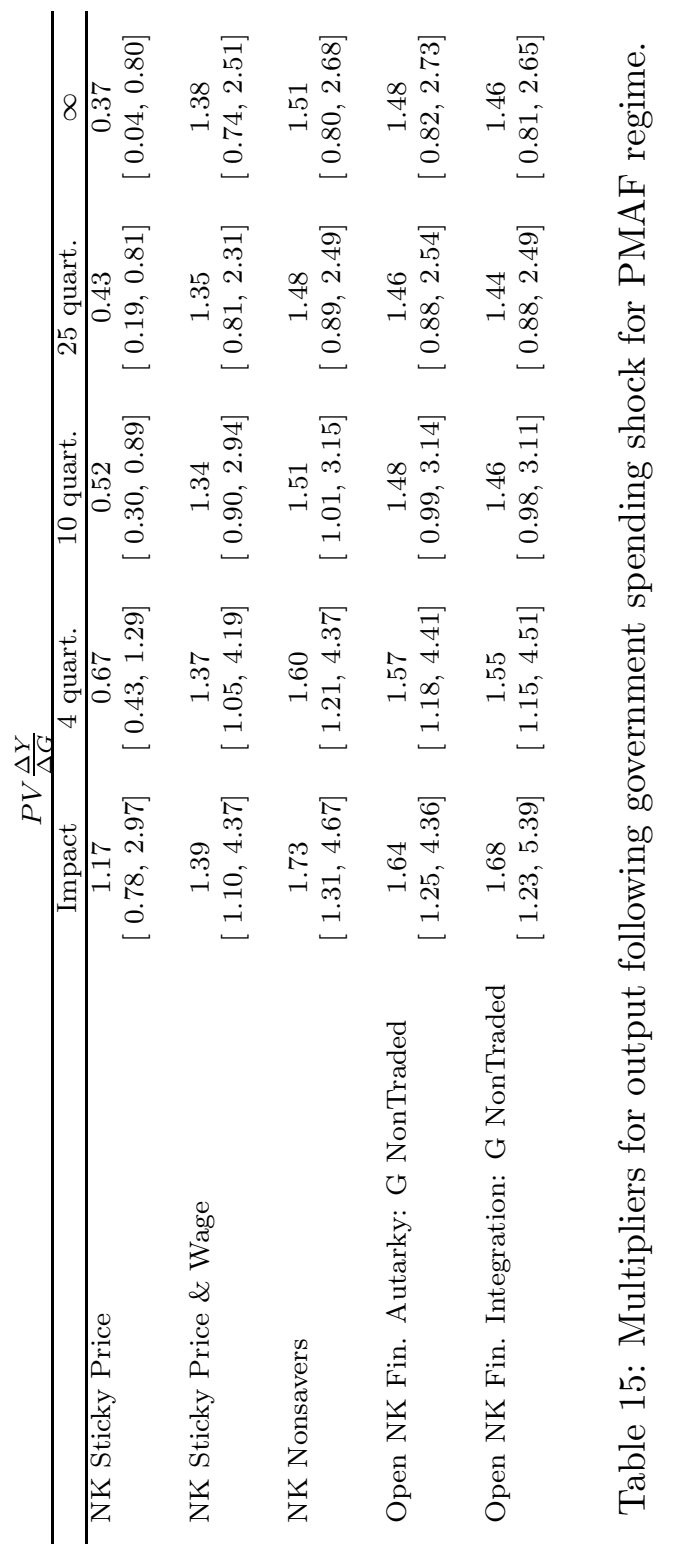




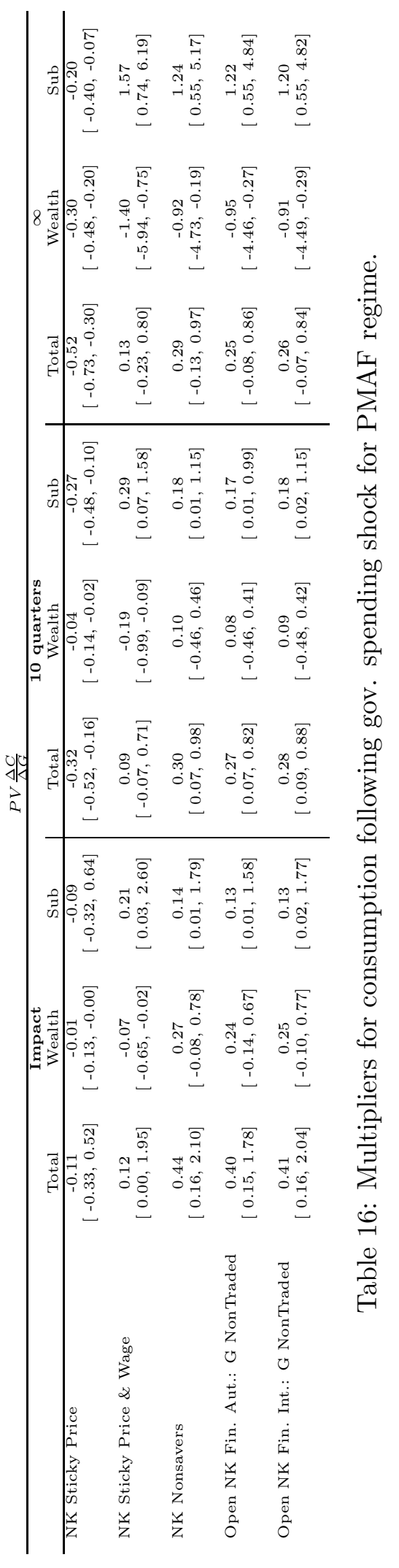




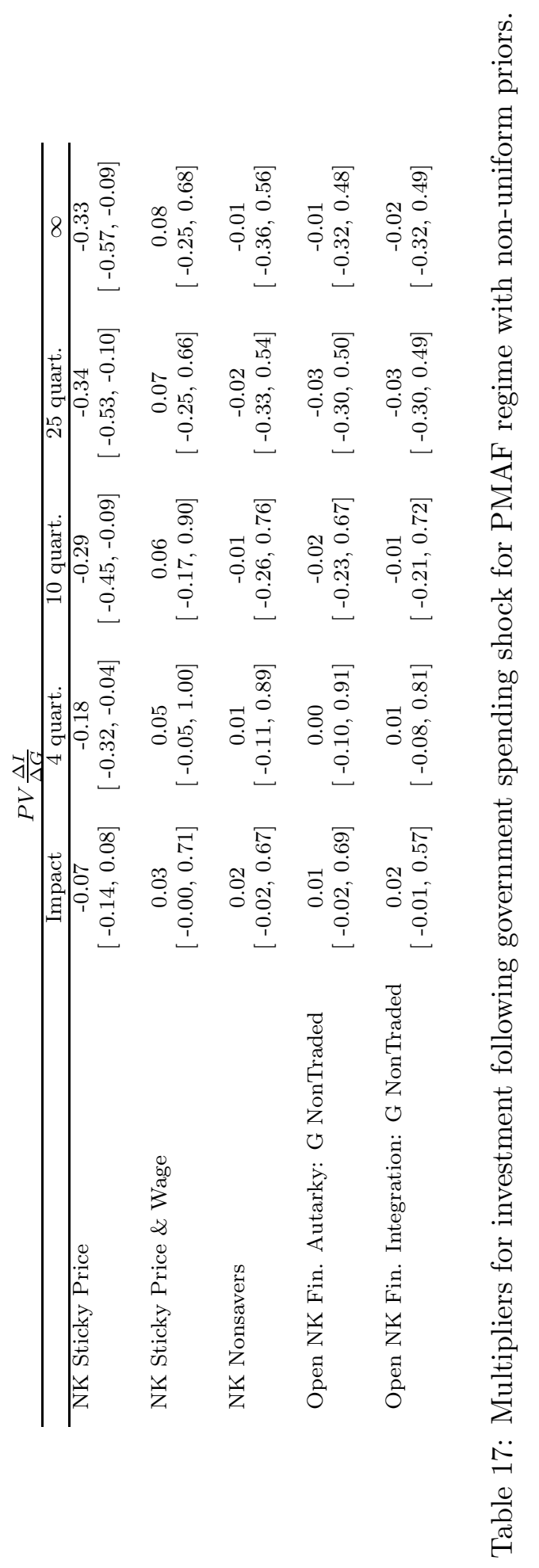




\begin{tabular}{lccc} 
& $\log \frac{p\left(\frac{\Delta Y}{\Delta G}=0.4 \mid A_{j}\right)}{p\left(\frac{\Delta Y}{\Delta G}=0.4 \mid A_{5}\right)}$ & $\log \frac{p\left(\frac{\Delta C}{\Delta G}=-0.11 \mid A_{j}\right)}{p\left(\frac{\Delta C}{\Delta G}=-0.11 \mid A_{5}\right)}$ & \\
\hline Model 1: Basic RBC & 13.19 & 2.25 & -5.44 \\
Model 2: Real Frictions & 15.19 & 0.55 & -0.38 \\
Model 3: NK Sticky Price & 11.27 & 2.47 & 0.18 \\
Model 4: NK Nonsavers & 7.02 & 0.20 & -0.05
\end{tabular}

Table 18: Log Bayes factors in favor of each model over model 5 (open economy with G nontraded), for various impact multipliers with benchmark priors.

\begin{tabular}{lccc} 
& $\log \frac{p\left(\frac{\Delta Y}{\Delta G}=0.4 \mid A_{j}\right)}{p\left(\frac{\Delta Y}{\Delta G}=0.4 \mid A_{5}\right)}$ & $\left.\log \frac{p\left(\frac{\Delta C}{\Delta G}=-0.11 \mid A_{j}\right)}{\Delta G}=-0.11 \mid A_{5}\right)$ & \\
\hline Model 1: Basic RBC & 0.46 & 1.01 & -4.71 \\
Model 2: Real Frictions & 2.35 & 0.80 & -0.14 \\
Model 3: NK Sticky Price & 0.74 & 1.29 & 0.10 \\
Model 4: NK Nonsavers & 0.17 & -0.07 & -0.07
\end{tabular}

Table 19: Log Bayes factors in favor of each model over model 5 (open economy with G nontraded), for various impact multipliers with uniform priors. 


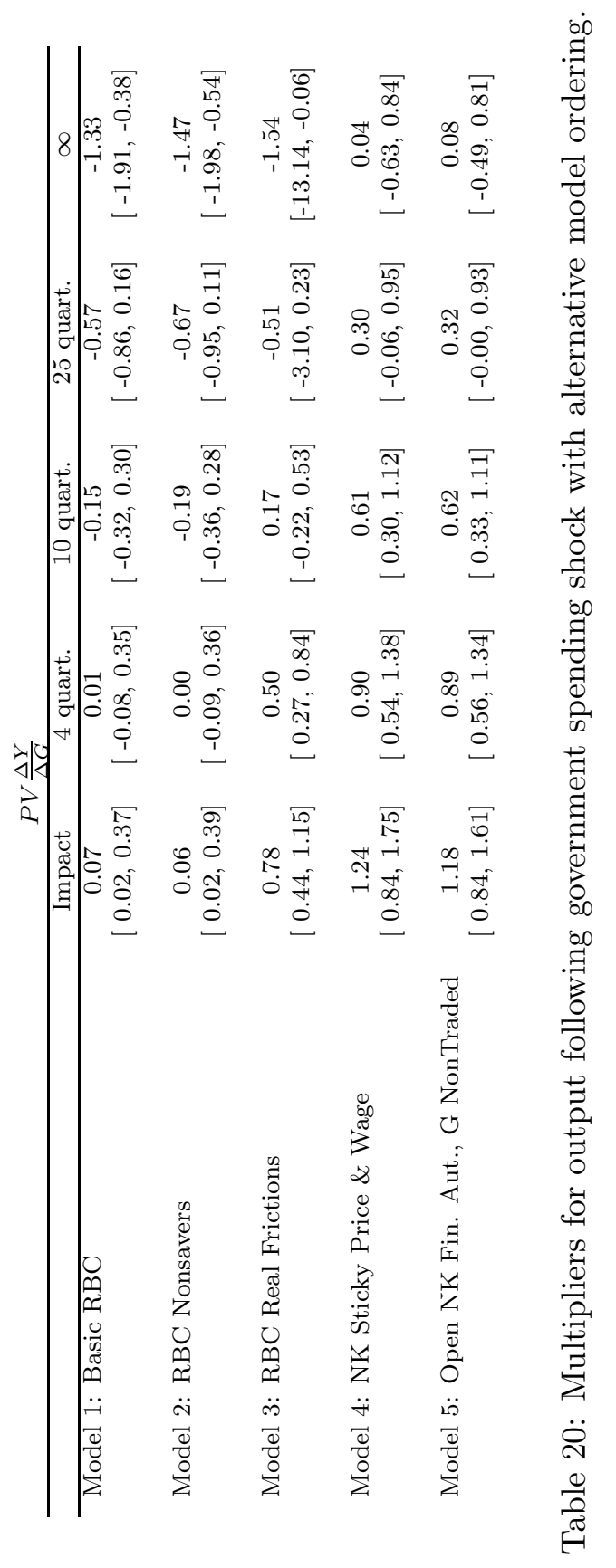

